\title{
Resilience in agri-food supply chains: a critical analysis of the literature and synthesis of a novel framework
}

\author{
Famie Stone and Shahin Rahimifard \\ Wolfson School of Mechanical, Electrical and Manufacturing Engineering, Loughborough University, Loughborough, UK
}

\begin{abstract}
Purpose - Resilience in agri-food supply chains (AFSCs) is an area of significant importance due to growing supply chain volatility. While the majority of research exploring supply chain resilience has originated from a supply chain management perspective, many other disciplines (such as environmental systems science and the social sciences) have also explored the topic. As complex social, economic and environmental constructs, the priority of resilience in AFSCs goes far beyond the company specific focus of supply chain management works and would conceivably benefit from including more diverse academic disciplines. However, this is hindered by inconsistencies in terminology and the conceptual components of resilience across different disciplines. The purpose of this study is to use a systematic literature review to identify which multidisciplinary aspects of resilience are applicable to AFSCs and to generate a novel AFSC resilience framework.

Design/methodology/approach - This paper uses a structured and multidisciplinary review of 137 articles in the resilience literature followed by critical analysis and synthesis of findings to generate new knowledge in the form of a novel AFSC resilience framework.

Findings - Findings indicate that the complexity of AFSCs and subsequent exposure to almost constant external interference means that disruptions cannot be seen as a one-off event; thus, resilience must concern the ability to not only maintain core function but also adapt to changing conditions.

Practical implications - A number of resilience elements can be used to enhance resilience, but their selection and implementation must be carefully matched to relevant phases of disruption and assessed on their broader supply chain impacts. In particular, the focus must be on overall impact on the ability of the supply chain as a whole to provide food security rather than to boost individual company performance.

Originality/value - The research novelty lies in the utilisation of wider understandings of resilience from various research fields to propose a rigorous and food-specific resilience framework with end consumer food security as its main focus.
\end{abstract}

Keywords Sustainability, Resilience, Food industry, Systematic literature review, Food security, Supply chain disruptions

Paper type Literature review

\section{Introduction}

It is increasingly accepted that supply chains in all forms face increasing volatility across a range of business parameters from energy cost, to raw material availability and currency exchange rates (Norrman and Jansson, 2004; Neiger et al., 2009; Christopher and Holweg 2011; Vlajic et al., 2013). Agri-food supply chains (AFSCs), which include all steps involved in production, manufacturing and distribution of food until its final consumption, not only share these general risks but also face their own unique vulnerabilities due to the limited shelf life of food, and variability in quality and availability of raw materials as organic products (Dani and Deep, 2010). There is evidence that these vulnerabilities may become more pronounced in future. For example, the quality and quantity of raw ingredients in many parts of the world will likely be challenged by an increased incidence of extreme weather linked to climate change (Karl, 2009; ESRC Public Policy Seminar, 2012; Allison et al., 2009).

The current issue and full text archive of this journal is available on Emerald Insight at: www.emeraldinsight.com/1359-8546.htm

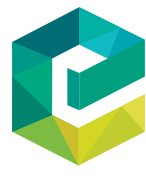

Supply Chain Management: An International Journal 23/3 (2018) 207-238

Emerald Publishing Limited [ISSN 1359-8546] [DOI 10.1108/SCM-06-2017-0201]
Moving beyond the projected impacts of climate change, the global population is expected to increase to over 9 billion by 2050, with much of the growth in current population projected to be in urban areas (Kastner et al., 2012). As many parts of the globe become wealthier, they are increasingly witnessing a dietary transition towards greater amounts of meat, dairy and more heavily processed foods (Suweis et al., 2015). This is often associated with negative impacts on dietary health and, with increasing pressure on environmental resources, is

(C) Jamie Stone and Shahin Rahimifard. Published by Emerald Publishing Limited. This article is published under the Creative Commons Attribution (CC BY 4.0) licence. Anyone may reproduce, distribute, translate and create derivative works of this article (for both commercial and non-commercial purposes), subject to full attribution to the original publication and authors. The full terms of this licence may be seen at http://creativecommons.org/licences/by/4.0/legalcode

The authors would like to thank the editor and two anonymous reviewers for their support and constructive comments. The authors would also like to acknowledge that this work was funded by the Engineering and Physical Sciences Research Council (EPSRC), as part of Grant Number EP/K030957/1.PI: Shahin Rahimifard. All data used are presented in full in this paper and, thus, are not located in a separate repository.

Received 8 December 2016

Revised 9 June 2017

21 August 2017

27 October 2017

Accepted 1 November 2017 
required to produce these types of food (Popkin, 1999; Godfray et al., 2010).

Herein lies a major challenge referred to as a "perfect storm" by many (Benton et al., 2012; Ingram et al., 2013). Not only are we likely to require more food to feed the world's growing population but also our ability to produce and deliver this food without disruption is likely to be constrained. It is widely projected that extreme weather volatility, energy price fluctuations and logistics restrictions, particularly in urban areas, will result in increased risk of disruption (Morgan, 2016; McMichael et al., 2007). In the past, food systems designed for economic efficiency, now must be re-evaluated for resilience. This is broadly understood to refer to the ability of an entity or system to react to disruptions (both foreseeable and unforeseeable) in such a way that core function is maintained (Barroso et al., 2011).

However, the contexts in which resilience is currently being explored are diverse, ranging from engineering (Pimm, 1984) and ecological systems science (Holling, 1973) to psychology (Luthar et al., 2000), supply chain resilience (SCRES) (Christopher and Peck, 2004) and community resilience (King, 2008). This has resulted in a fragmented and sometimes inconsistent research field. For example, depending on the research context, the "definition" and thus overall goal of resilience can vary widely. Furthermore, there is often inconsistency in the physical "Elements"; for example, spare inventory or alternate suppliers, which are suggested to help make an entity resilient. In turn, the "Strategies" (i.e. how an entity decides which "element" to use in a given situation) used by entities are often highly variable. The terms "Definition", "Elements" and "Strategies" have been carefully worded so as to be consistent with terms identified as key principles of resilience in the literature (Christopher and Lee, 2004; Hohenstein et al., 2015; Pereira et al., 2014; Kamalahmadi and Parast, 2016).

This fragmentation has not gone unnoticed, particularly in the supply chain management (SCM) field. Ponomarov and Holcomb (2009), in their extensive review, consider a number of the different definitions and propose a synthesised, comprehensive definition of SCRES. Hohenstein et al. (2015) develop this and systematically identify commonly cited "elements" and the phases of disruption in which they are useful. Building on this, Kamalahmadi and Parast (2016) developed the concept of resilience elements by considering strategies by which an organisation could implement such resilience elements.

Where many of the aforementioned works have tended to focus on organisational competitive advantage (even if it in the context of a wider supply chain) in the face of adversity, the focus of attempts to enhance resilience in AFSCs should concern the unbroken flow of safe and appropriate food to end consumers in the face of disruption (Tendall et al., 2015). This means that any resilience definitions, elements and strategies will likely need to be adapted to suit an AFSC context. One possible way of achieving this would be to expand SCM understandings of resilience to consider other research perspectives on resilience such as community resilience and ecological systems resilience; both of these areas not only play a key role in supporting AFSCs but also are likely to suffer if AFSCs fail (Falkowski, 2017). This is particularly relevant for resilience "elements" because SCM works have tended to focus on the most commonly cited ones, particularly flexibility and redundancy (Hohenstein et al., 2015). Yet there are many less commonly explored "elements" of resilience, particularly from non-SCM perspectives, such as "adaptive management" and "community resources", that would feasibly be useful in designing an AFSC-specific understanding of resilience (Smith et al., 2016; Sinclair et al., 2014; Milestad and Darnhofer, 2003).

This work therefore seeks to address these gaps through the following core review question:

Q1. How can the multidisciplinary concept of resilience be applied to AFSCs?

To answer this question, a holistic approach is taken to review the literature for definitions, elements and strategies that are important for resilience in AFSCs (including understandings from SCM, operations management, ecological systems and social systems). The findings are then synthesised into a food security-orientated framework for implementing resilience in developed world AFSCs.

As such, the paper is structured as follows. First, the methodology which describes the systematic literature review (SLR) process in detail is presented. The paper then proceeds to descriptively analyse the resilience literature to identify broad trends in the approaches of different research fields to resilience before focussing in detail on the fit of the literature to the identified review question and its associated sub-questions. Next, the results of the SLR are applied to contemporary AFSC structures to generate a holistic framework that defines and considers AFSC-specific resilience elements and strategies. Finally, the implications of the review findings in terms of both supply chain theory and practice are considered before concluding remarks, and recommendations for future research are presented.

\section{Methodology}

The requirements for selecting the methodology were that it must enable the identification, analysis and synthesis of secondary data from a broad range of disciplines into a holistic understanding based on fit to a specific review question. For this reason, the SLR process was chosen. The SLR approach differs from more general literature reviews in terms of comprehensiveness (ensuring that all relevant material is included), specificity (identification of salient points through fit to carefully selected review questions) and transparency/replicability (adding reliability to findings) (Tranfield et al., 2003). Crucially, the SLR approach also enables synthesis of ideas which not only aids wider scholarly dissemination of key concepts and advances the research field but also effectively creates new knowledge, thus being of equal value to new research (Rousseau et al., 2008; Light and Pillemer, 1986). With this in mind, the review methodology used in this paper followed the method of Denyer and Tranfield (2009) and consisted of five distinct steps which are outlined in Figure 1 and which are now described in detail. 
Figure 1 Systematic review methodology

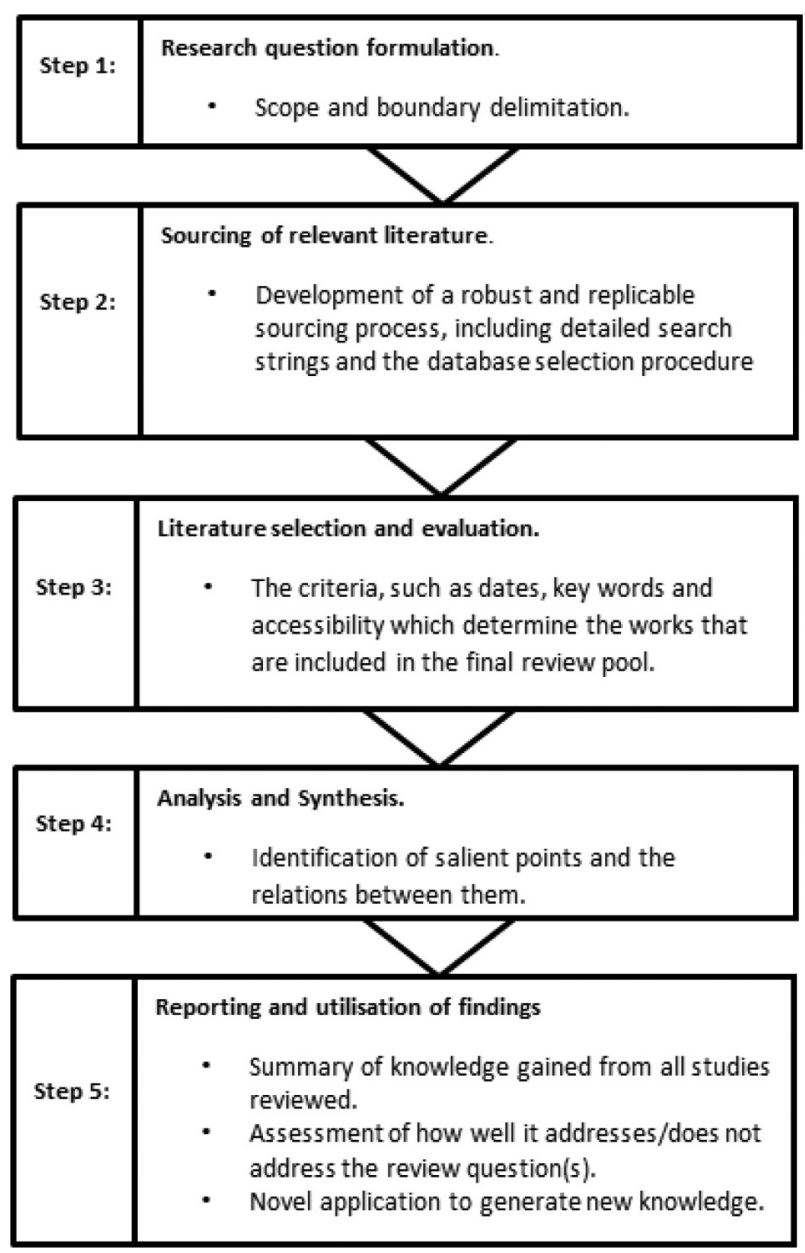

Source: Adapted from Denyer and Tranfield (2009)

\subsection{Step 1: review question formulation}

The first step in an SLR is the formulation of a specific, purposeful, review question to determine the scope and focus of the review. The aim of this review is to comprehensively identify definitions, elements and strategies for resilience and to develop a holistic framework for how they apply to AFSCs. Hence, this review aims to address $Q 1$.

To help structure the answer to this question, three subquestions have been identified as follows:
Q1.1. What definitions of resilience are appropriate for describing AFSCs?

Q1.2. What resilience elements and strategies can be applied to $\mathrm{AFSC}$ resilience?

Q1.3. How can appropriate definitions, elements and strategies be conceptually linked to provide a food security focussed framework of AFSC resilience?

\subsection{Step 2: locating relevant literature}

The purpose of this phase is to design search criteria in such a way as to ensure the identified literature is comprehensive enough to capture all salient points relevant to the review question (Denyer and Tranfield, 2009). One of the key research gaps driving this review was the need to cover a variety of fields relevant to AFSCs, not simply SCM, and therefore avoiding bias in selection was vital. Therefore, the following multi-database, cross-disciplinary online citation services were used: Google Scholar, Web of Science, ProQuest, Science Direct, Wiley Online, Emerald and Scopus. Consistent with a number of other SLRs in the area of resilience, this paper used a number of defined keywords as search criteria as summarised in Table I. The search was performed in December 2016, and the search for keywords was restricted to title and abstract. Keywords were initially selected based on the authors' collective knowledge of the field which enabled them to draw up a long list of terms commonly associated with resilience in the literature. Following standard SLR practice (Hohenstein et al., 2015; Kamalahmadi and Parast, 2016), these were critiqued and validated through consultation with other research colleagues allowing us to arrive at the shortlist presented in Table I.

Search strings were composed of primary keywords and secondary keywords. The primary search phrase used in all databases was either "Community", "Socio-Ecological System" or "Supply Chain". Each primary search phrase was accompanied by AND "resilience/resiliency". In addition, each search involved a secondary keyword which was one of either: "Risk/Risk Management", "OR Vulnerability”, "OR Volatility", "OR Security", "OR Mitigation” or "OR Business Continuity". These variations were run exhaustively, e.g. "Community" AND "Resilience" AND "Security".

\subsection{Literature selection and evaluation}

From the initial search criteria, this review sourced a total of 1,270 articles. To maintain transparency and to ensure fit of

Table I Literature sourcing key words

\begin{tabular}{lll}
\hline Primary phrases & Secondary phrases & Database search strings \\
\hline Supply chain AND & Risk/risk management & Primary and secondary keywords were applied in databases as follows. Searching within \\
resilience/resiliency & OR Vulnerability & abstract and title: \\
Community AND & OR Volatility & Key word: ONE of either Supply chain/community/socio-ecological system \\
resilience/resiliency & OR Security & AND: Resilience/resiliency \\
Socio-ecological AND & OR Mitigation & AND: Risk/risk management OR vulnerability OR volatility OR security OR mitigation OR business \\
resilience/resiliency & OR Business & continuity \\
& continuity & \\
\hline
\end{tabular}


identified material to the review question, stringent selection criteria were applied to this initial search pool. While material was not limited by publication date, materials were restricted to those published in the English language. Additionally, in line with other SLRs in the area of resilience (Hohenstein et al., 2015; Kamalahmadi and Parast, 2016), material was limited to peer reviewed publications as an indicator of the academic rigour of identified literature (Light and Pillemer, 1986). Once duplicates, non-peer reviewed results and non-English publications were excluded, and the remaining pool numbered 239 articles. Scanning of Introductions and Conclusions provided a better understanding of the fit of the material to the review question and its associated sub-questions. At this stage, 104 articles were excluded due to either being inaccessible (six articles), or being beyond the scope of AFSC-relevant resilience definitions, elements and strategies. Work cited in all accepted articles was also scanned for titles that matched the keyword criteria. In total, this provided a final review size of 137 articles (Figure 2).

\subsection{Step 4: analysis and synthesis}

The objective of this stage was to analyse and synthesise the final literature pool of 137 articles to identify new knowledge about the multi-disciplinary concept of food SCRES that would not have been apparent from reading each of the papers individually. Analysis was conducted using a Microsoft Excel spreadsheet to record summaries of the positions of each of the 137 articles regarding the key resilience concepts of definition, elements and implementation strategies. Synthesis was achieved via an integrative approach which compared multidisciplinary works for convergent, divergent and co-evolving understandings of the aforementioned resilience concepts and used the results to build a synergistic conceptual framework of food SCRES. This was chosen over alternative approaches to synthesis, such as aggregative approaches as evidence suggests it better suits heterogeneous source material (Rousseau et al., 2008).

\subsection{Step 5: reporting and using the findings}

In this stage of an SLR, the findings from the analysis of the entire review pool, the relationships between salient concepts and the extent to which this information has addressed the review questions are reported (Denyer and Tranfield, 2009). Typically, synthesised findings can also be applied in a novel context to help generate new understandings of the relationships between concepts that may have been studied in isolation in the literature. In the context of this paper, Section 3 reports the findings of the review in relation to the review question and sub-questions. It proceeds to then synthesise and apply the findings in the form of a holistic framework that models resilience in AFSCs.

\section{Findings}

This section presents the analysis and synthesis of the final literature pool of 137 articles. First, to understand how resilience as a concept has developed over time and across multiple disciplines, a descriptive analysis of articles by publication date, publication journal, subject area and methodology is performed. The literature is then investigated
Figure 2 Review process for literature selection and evaluation

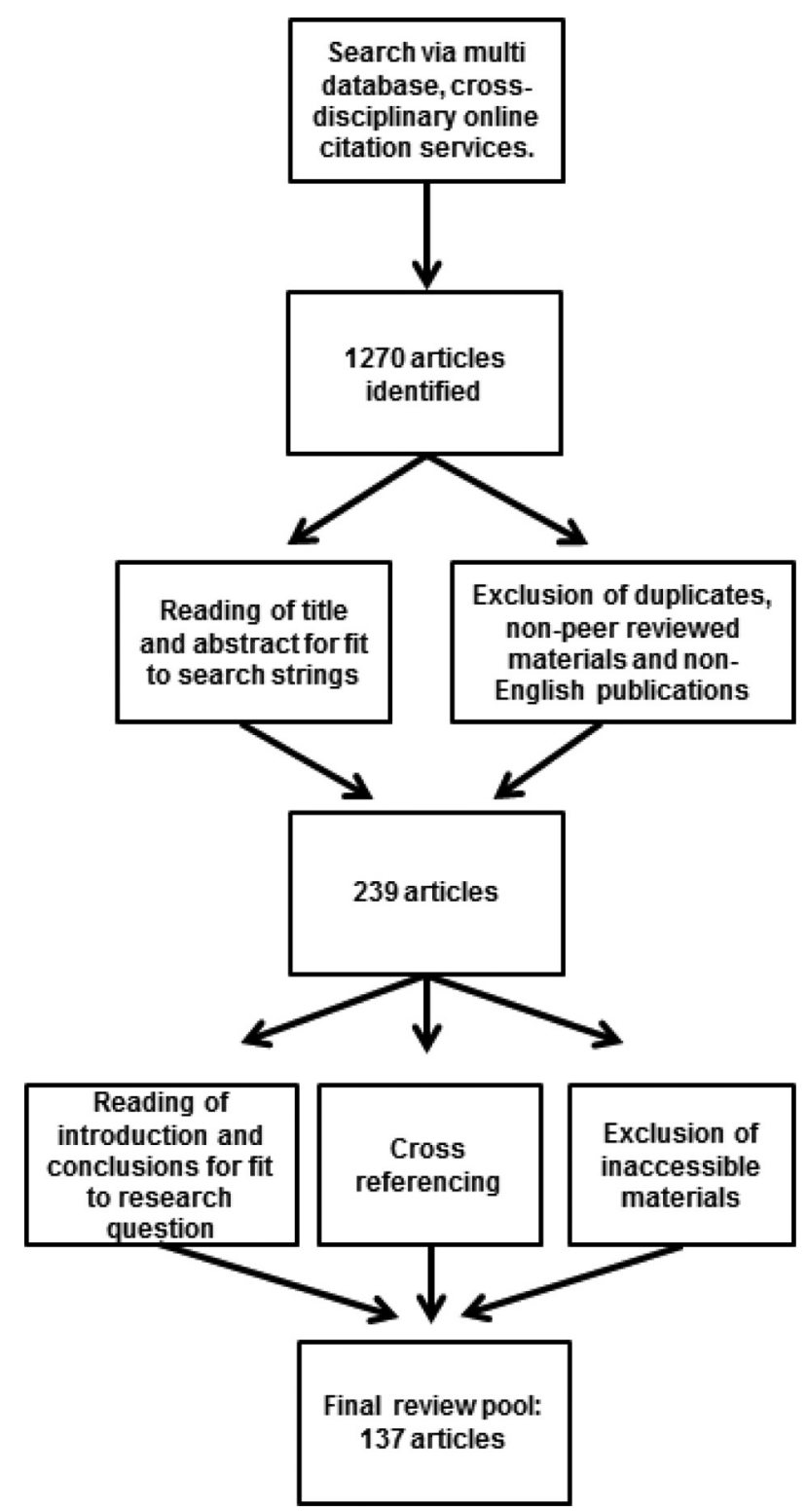

more specifically from the perspective of each of the three review sub-questions. Finally, the salient concepts from each of the review sub-questions are unified in a novel framework modelling key concepts relating to resilience in AFSCs.

\subsection{Descriptive analysis}

Table II highlights that 40 per cent of the final 137 works reviewed originated in one of the leading seven journals of which Supply Chain Management: An International fournal and International fournal of Production Economics were the most popular. All of the aforementioned journals represent either the fields of SCM or operations management, in which the priority of resilience efforts tended to focus on business continuity and particularly competitiveness of individual actors (Hohenstein et al., 2015; Pereira et al., 2014; Elleuch et al., 2016a, 2016b). Indeed, when all publication sources are considered, 75 per 
Table II Review material by source

\begin{tabular}{|c|c|c|c|}
\hline Academic journal & Authors & No. Papers & $\%$ \\
\hline $\begin{array}{l}\text { Supply Chain Management: an } \\
\text { International Journal }\end{array}$ & $\begin{array}{l}\text { Scholten and Schilder (2015), Scholten et al. (2014), Pereira et al. } \\
\text { (2014), Johnson et al. (2013; Leat and Revoredo-Giha (2013), Gligor } \\
\text { and Holcomb (2012), Jüttner and Maklan (2011), Aramyan et al. } \\
\text { (2007), Taylor and Fearne (2006), Barratt (2004), Finch (2004) }\end{array}$ & 11 & 8.1 \\
\hline International Journal of Production & Kamalahmadi and Parast (2016), Pal et al. (2014), Vlajic et al. (2012), & 11 & 8.1 \\
\hline Economics & $\begin{array}{l}\text { Schmitt and Singh (2012), Trkman and McCormack (2009), Thun and } \\
\text { Hoenig (2011), Blome and Schoenherr (2011), Tang and Musa (2011), } \\
\text { Wagner and Neshat (2010), Tang (2006), Sharifi and Zhang (1999) }\end{array}$ & & \\
\hline $\begin{array}{l}\text { International Journal of Production } \\
\text { Research }\end{array}$ & $\begin{array}{l}\text { Munoz and Dunbar (2015), Ho et al. (2015), Tukamuhabwa et al. } \\
\text { (2015), Gunasekaran et al. (2011), Kim et al. (2015), Wagner and } \\
\text { Neshat (2012), Spiegler et al. (2012), Diabat et al. (2012), Wu et al. } \\
\text { (2013) }\end{array}$ & 9 & 6.6 \\
\hline $\begin{array}{l}\text { International Journal of Physical } \\
\text { Distribution \& Logistics } \\
\text { Management }\end{array}$ & $\begin{array}{l}\text { Durach et al. (2015), Wieland and Wallenburg (2013), Christopher and } \\
\text { Holweg (2011), Skipper and Hanna (2009), Peck (2005), Norrman and } \\
\text { Jansson (2004), Christopher and Lee (2004), Van der Vorst and Beulens } \\
\text { (2002) }\end{array}$ & 8 & 5.8 \\
\hline Journal of Business Logistics & $\begin{array}{l}\text { Pettit et al. (2013), Boone et al. (2013), Zsidisin and Wagner (2010), } \\
\text { Pettit et al. (2010), Zacharia et al. (2009), Wagner and Bode (2008), } \\
\text { Manuj and Mentzer (2008), McKinnon (2006) }\end{array}$ & 8 & 5.8 \\
\hline Journal of Operations Management & $\begin{array}{l}\text { Ambulkar et al. (2015), Kim et al. (2015), Braunscheidel and Suresh } \\
\text { (2009), Neiger et al. (2009), Swafford et al. (2006) }\end{array}$ & 5 & 3.6 \\
\hline $\begin{array}{l}\text { International Journal of Logistics: } \\
\text { Research and Applications }\end{array}$ & $\begin{array}{l}\text { Colicchia and Strozzi (2012), Dani and Deep (2010), Peck (2005), Tang } \\
\text { (2006), Jüttner et al. (2003) }\end{array}$ & 5 & 3.6 \\
\hline $\begin{array}{l}\text { The International Journal of } \\
\text { Logistics Management }\end{array}$ & $\begin{array}{l}\text { Ponomarov and Holcomb (2009), Christopher and Peck (2004), Sheffi } \\
\text { (2001) }\end{array}$ & 3 & 2.2 \\
\hline $\begin{array}{l}\text { International Journal of Operations } \\
\text { and Production Management }\end{array}$ & $\begin{array}{l}\text { Stevenson and Spring (2007), Ritchie and Brindley (2007), Hoek et al. } \\
\text { (2001) }\end{array}$ & 3 & 2.2 \\
\hline $\begin{array}{l}\text { International Federation of } \\
\text { Automatic Control }\end{array}$ & $\begin{array}{l}\text { Elleuch et al. (2016a, 2016b), Elleuch et al. (2016a, 2016b), Ivanov et } \\
\text { al. (2015) }\end{array}$ & 3 & 2.2 \\
\hline Global Environmental Change & McDaniels et al. (2008), Milman and Short (2008), Folke (2006) & 3 & 2.2 \\
\hline $\begin{array}{l}\text { Production Planning \& Control: The } \\
\text { Management of } \\
\text { Operations }\end{array}$ & Colicchia et al. (2010), Asbjornslett (1999), Vlajic et al. (2013) & 3 & 2.2 \\
\hline Transport Research & $\begin{array}{l}\text { Fahimnia and Jabbarzadeh (2016), Lam and Bai (2016), Yang and Xu } \\
\text { (2015) }\end{array}$ & 3 & 2.2 \\
\hline Other & $\begin{array}{l}\text { Paloviita et al. (2016), Manning and Soon (2016), Annarelli and Nonino } \\
\text { (2016), Tendall et al. (2015), Suweis et al. (2015), Caschili et al. (2015), } \\
\text { Todo et al. (2015), Macfadyen et al. (2015), Fałkowski (2015), Gölgeci } \\
\text { and Ponomarov (2015), Habermann et al .(2015), Rodriguez-Nikl } \\
\text { (2015), Aigbogun et al. (2014), Brandon-Jones et al. (2014), Carvalho } \\
\text { et al. (2014), Soni et al. (2014), Redman (2014), Allen et al. (2014) } \\
\text { Dubey et al. (2014), Smith et al. (2014), Ingram et al. (2013), Kirwan } \\
\text { and Maye (2013), Sinclair et al. (2014), Davoudi et al. (2012), Ghadge } \\
\text { et al. (2012), Azevedo et al. (2012), Carvalho et al. (2012a, 2012b), } \\
\text { Ponis and Koronis (2012), Carvalho et al. (2012a, 2012b), Barthel and } \\
\text { Isendahl (2013), Carvalho et al. (2012a, 2012b), Berle et al. (2011), } \\
\text { Rose (2011), Giannakis and Louis (2011), Derissen et al. (2011), } \\
\text { Cimellaro et al. (2010), Higgins et al. (2010), Ford (2009), Stecke and } \\
\text { Kumar (2009), Neureuther and Kenyon (2009), Bakshi and Kleindorfer } \\
\text { (2009), Ratick et al. (2008), King (2008), Wagner and Bode (2008), } \\
\text { Lodree and Taskin (2008), Folke (2006), Walker et al. (2006), Tomlin } \\
\text { (2006), Fiksel (2003), Faisal and Banwet. (2006), Manyena (2006), } \\
\text { Jüttner (2005), Lebel et al. (2006), Kleindorfer and Saad (2005), Fraser } \\
\text { et al. (2005), Cox and Chickssnd (2005), Carvalho et al. (2005), Sheffi } \\
\text { and Rice (2005), Fiksel (2003), Milestad and Darnhofer (2003) }\end{array}$ & 62 & 45.2 \\
\hline
\end{tabular}


cent of all articles considered in this review have an SCM or operations management origin. However, less common but still important sources of resilience literature were found in journals from a range of other disciplines which included ecological systems, social systems and engineering/physical systems as outlined in Figure 3. These alternative disciplines are an important source of resilience research, particularly publications with a focus on social systems, where the priority of resilience tends to be on the adaptive capacity of complex systems (Tendall et al., 2015; Milestad and Darnhofer, 2003). The authors feel that this supports the previous contention that existing works which explore resilience from an SCM and/or operations management perspective, with their focus on individual business continuity and competitive advantage, are not always readily transferrable to the topic of AFSCs.

Another notable observation is that all of the articles reviewed were published post-2000 with 65 per cent being published post-2010, suggesting that interest in the application of resilience as a concept is recent and growing phenomena. Evidence suggests that this is in response to a number of wide ranging and unexpected disruptions including Hurricane Katrina, the Icelandic eruptions at Eyjafjallajökull in 2010, the Fukushima nuclear disaster, as well as major terrorist incidents such as the 9/11 attacks in America and the 7/7 attacks in the UK (Kinsey et al., 2007; Sheffi, 2001; Scholten et al., 2014; Christopher and Lee, 2004).

Figure 4 analyses the literature according to its adopted methodology. Methodology is classified according to four categories borrowed from Natarajarathinam et al. (2009): conceptual/theoretical, analytical, empirical and applied. The term conceptual/theoretical refers to works which synthesise or develop existing understanding of SCRES but which

Figure 3 Analysis of literature by research context and specificity to AFSCS

\section{Agri-Food Related Works}

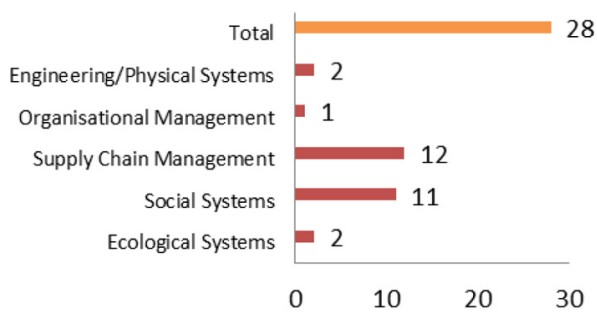

\section{Non Agri-Food Related Works}

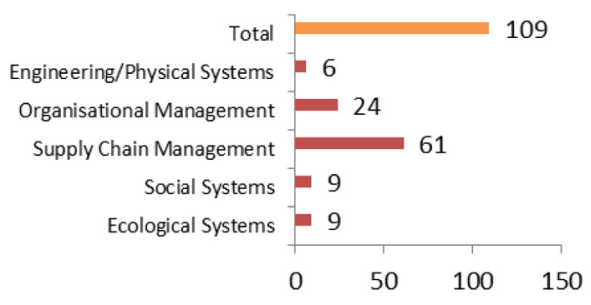

Figure 4 Methodological approaches taken to investigating resilience in the literature

\section{Methodological approaches to studying resilience}

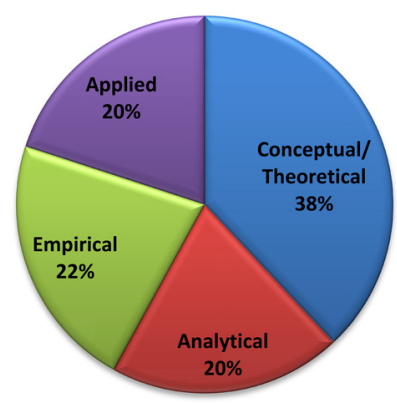

are not supported by any empirical work. Literature reviews are classed within this category. Works involving substantial simulation or mathematical modelling of a real-world supply chain issue with specified parameters fall within the analytical category. Articles that involve the collection of real world data and its evaluation are classed as empirical. Finally, case studies, interviews and other forms of gathering thoughts and opinions are classed as applied. Ultimately, the most common form of methodological approach was conceptual/ theoretical which accounted for 52 (38 per cent) of the reviewed articles.

The authors of this review concur with Hohenstein et al. (2015) that this represents the importance of theory building in what is still a relatively new research area. Encouragingly, in recent years, there have been an increasing number of empirical works, case-specific applied works and mathematical analysis-based works which suggests that the focus is moving away from defining resilience towards trying to understand what its functional "elements" are. However, a large number of such works attempt to measure or model resilience based on a very small number of commonly cited "elements", particularly flexibility and redundancy; for example, Braunscheidel and Suresh (2009), Skipper and Hanna (2009) and Datta et al. (2007). While such works are highly valuable in the sense that there is a real need to empirically validate emerging resilience theories, there is a risk that resilience as a practical target could be oversimplified. This descriptive analysis of the resilience literature will now be used as a base from which to explore each of the review sub-questions individually.

\subsection{Addressing Q1.1}

This section addresses review sub-question one by exploring how resilience has been defined as a concept by different research fields (Figure 3). Resilience can best be thought of as an umbrella term for a range of linked factors that help ensure continuity in the face of disruption (Tendall et al., 2015). Before exploring the concept in more detail, it is important to provide clarity on the relationship between resilience and the 
similar terms of "sustainability" and "robustness" which investigation suggests are sometimes used interchangeably. Using the definition of sustainability outlined in the Brundtland Report: "meeting the needs of the present without compromising the ability of future generations to meet their own needs", sustainability can be described as a normative measurement for assessing long-term performance against ideal environmental, economic and social standards (Derissen et al., 2011).

By contrast, resilience is more of a descriptive methodology concerning short-term ability to withstand and/or adapt to disturbance (Tendall et al., 2015). As such, it is a key attribute for any organisation with long-term sustainability goals in complex systems with ever-changing drivers. Thus, an organisation can be resilient and unsustainable, but not sustainable without the presence of resilience, as it would be too susceptible to short-term derailment from excessive exposure to disruption. Robustness is another term which is related to resilience and frequently used interchangeably. However, the two are separate terms, with robustness prioritising strength to withstand disturbances, whereas resilient systems include flexibility to adapt to disturbance (Asbjornslett, 1999; Jüttner et al., 2003). In this way, it is possible to see robustness as a component of resilience, and in turn, resilience as a short-term enabler of long-term sustainability (McDaniels et al., 2008). To summarise, while these terms would therefore appear to be synergistic, it is erroneous to use them interchangeably (Redman, 2014).

Moving on to focus on resilience, while a relatively new addition in the context of SCM and AFSCs in specific, it is by no means a new concept. The term has Latin origins, stemming from the word "resi-lire", meaning to spring back and was first used by physicists to describe the stability of materials and their ability to resist external shocks (Manyena, 2006). It entered popular use in the field of Ecology in the 1960 s and from there began to be translated to a range of new subject fields aided by a seminal article by Crawford Stanley Holling in 1973 (Holling, 1973). This article divided resilience into two distinct definitions that are commonly used today: engineering resilience and ecological resilience.

In the engineering definition, resistance to disturbance and the speed by which the system returns to a state of equilibrium are the marks of resilience. The phrase "a state of equilibrium" refers to the notion of optimal day to day operations (Rose, 2011). Heavy emphasis is placed on return time, efficiency, constancy and predictability, which it is claimed are the marks of a sound engineering design and hence the name (Holling, 1996). In the ecological definition, resilience is also measured by resistance to disturbance and speed of return to a state of equilibrium, but this definition also accepts that there are multiple possible equilibriums that the system could flip into depending on the magnitude of the disturbance.

It has been pointed out that a major shortcoming of both the engineering and ecological definitions of resilience is that they presume closed systems within which different actors can establish states of equilibrium. This is clearly not the case in something as complex as a food system where intertwined social, environmental, economic and political factors drive constant change across key operating parameters. In response to this, several authors have proposed a third definition of resilience which has been termed "Evolutionary" or "Adaptive" Resilience (Walker et al., 2006; King, 2008; Folke, 2006; Ambulkar et al., 2015). For consistency, we use the term adaptive resilience from now onwards in this review.

Adaptive resilience describes complex social-ecological systems where the interactions between different scales (for example, from individual species, to forests, to entire ecosystems), periods (referred to as temporal scales) and geographic distances (referred to as spatial scales) are all considered vital for overall system resilience. As such, there cannot be a "state of equilibrium" because external interference is continuous. Instead, resilience is something that is cyclical and cumulatively developed by a continual process of adaptation and learning from ongoing disturbances. It has been proposed that this continuous adaptive cycle has four distinct stages: exploitation, conservation, release and reorganisation as shown in Figure 5 (Allen et al., 2014; Walker et al., 2006).

The first phase is exploitation, which in the context of a business, is marked by use of readily available resources to form structure and core business priorities. An example might be that of a new start-up company with a novel product and market dominance. However, as an organisation grows, it will eventually reach a point where its size binds ever larger quantities of resources and its connectivity increases cross-scale interactions, known as the conservation phase. The existence of the phase is supported by evidence collected by Peck (2005) in multi-sectorial supply chain interviews. An example view expressed by a consultant in Electronics Manufacturing is:

It's when the supply chain is supposed to be in the established steady state that it is most vulnerable, because that's the point when it's most susceptible to external effects. That's when most people are trying to optimise and reduce control limits to reduce the variability of the process, but external risks may have changed the original scenario. (Peck, 2005).

In AFSCs in specific, this phase has been likened to contemporary drives towards intensification of agriculture and centralisation of factories and distribution centres, representing accumulation of capital and growing interconnectivity. Other

Figure 5 The adaptive cycle of system dynamics

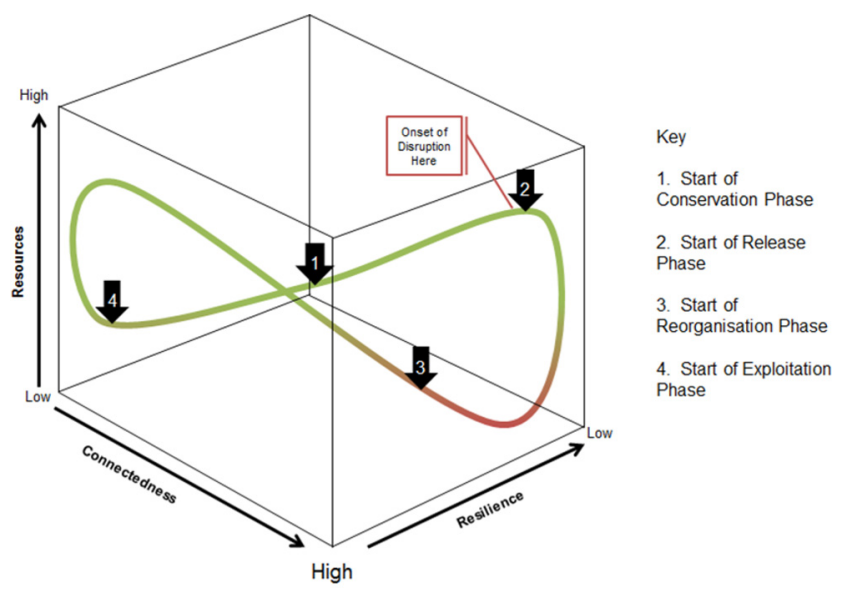

Source: Adapted from information provided by Walker et al. (2006) (reviewed) which in turn is based on previous work by Gunderson, 2001) (not reviewed) 
assets bound up in AFSCs include significant amounts of land, water, carbon and other nutrients embodied in food (Fraser et al., 2005).

Whether from the perspective of an entire food system or a single business within the existing system, this phase is where susceptibility to disturbance is at its highest because so many assets are tied up in the current way of doing things and connectivity means exposure is at its highest. There is the potential for significant loss of resources if a big enough disturbance occurs, and this is known as the "Release" phase. This does not necessarily comprise pure financial loss, but might also concern loss of resources bound up in no longer tenable business structures. The business does not necessarily collapse at this point, but there will need to be some sort of adaptation (the Reorganisation Phase) at which point the cycle begins again (Davoudi et al., 2012).

Influencing the adaptive cycle are three components: "resilience" (capacity to absorb change), "adaptability" (capacity to evolve a given form of operation) and "transformability" (ability to completely change an untenable system of operation). These are effectively control mechanisms with which an organisation can influence the adaptive cycle stages (Figure 5). The adaptive cycle also differs from the engineering and ecological definitions of resilience by its underlying consideration of "Panarchy" (Allen et al., 2014). This represents complexity in a system where disruptions do not necessarily have to originate within the same period or geographic proximity as the focal organisation. This means that the relationships between cause and effect of a disturbance do not necessarily have to be linear. As such, small influences such as the input of single staff members in the face of disruption can have just as much, or even more, impact than large scale interventions. Such unpredictability challenges the adequacy of conventional risk management tools, such as extrapolation of past trends as a way of forecasting future events (Trkman and McCormack, 2009). The key differences between the engineering, ecological and evolutionary definitions of resilience are summarised in Table III.

In Table IV, the review pool is analysed according to which of the three definitions authors adopt. In total, 48 of the 137 articles being reviewed offered a definition for resilience. As
Q1.1 concerns identifying suitable definitions of resilience for AFSCs, literature definitions were compared on whether they were from articles considering AFSCs in specific, or from different perspectives on resilience. Thirteen of the articles offering definitions considered AFSCs in specific (although this specificity was not always obvious in the definition provided) and 35 were more general in focus. The broader research contexts of the review articles were also compared to identify if certain research fields prioritise a specific type of definition.

Engineering definitions were distinguished by their focus solely on resisting and recovering rapidly from external disturbances with minimal impact on system deliverables. Ecological definitions, on the other hand, focussed on the amount of change a system can endure and recover from, possibly involving moving to a new equilibrium, while maintaining core functions. Adaptive definitions made no mention of states of equilibrium but instead focussed on adaptive change to volatile external operating environments. As such, in addition to mention of ability to "resist" and "recover", the ability to "adapt" or "reorganise", whether in response to, or in anticipation of a disruption was common in such definitions (Wu et al., 2013; King, 2008; Cimellaro et al., 2010).

It was identified that overall there was a slight preference for the adaptive definition of resilience. This is particularly true in works that were AFSC specific in focus, many of which hailed from a social systems perspective. Such works frequently considered resilience at community and societal scales and prioritised a system's ability to continue providing food, rather than economic viability of individual businesses within the chain. Here, end consumers and the different AFSCs that feed them are considered within the sphere of the wider natural world, where change is constant and control over that change by any given actor is small. For example, as complex socialecological systems, AFSCs are dependent on a number of ecosystem services to produce food, and significant socialeconomic factors to manufacture and transport food. Each of these is exposed to vulnerabilities, for example, in the form of policy interventions, consumer demand and environmental management.

Table III Comparison of engineering, ecological and adaptive definitions of resilience

\begin{tabular}{|c|c|c|}
\hline Criteria for comparison & Engineering definition of resilience & Ecological definition of resilience \\
\hline Definition & $\begin{array}{l}\text { 'The ability of a system to return to an equilibrium or steady- } \\
\text { state after a disturbance' (Walker et al., 2006; Fiksel, 2003; } \\
\text { Folke 2006) }\end{array}$ & $\begin{array}{l}\text { 'The magnitude of the disturbance that can be absorbed } \\
\text { before the system changes its structure' (Tendall et al., 2015; } \\
\text { Fiksel, 2003; Folke, 2006) }\end{array}$ \\
\hline Stance on equilibrium & $\begin{array}{l}\text { Focus is on returning to existing equilibrium as soon as } \\
\text { possible (Folke, 2006; Elleuch et al., 2016a, 2016b) }\end{array}$ & $\begin{array}{l}\text { Acceptance of multiple possible equilibriums, change to } \\
\text { which could either be forced or presented as a possibility by } \\
\text { disruption. Focus therefore is on is on identifying the optimal } \\
\text { equilibrium state which may or may not have been the } \\
\text { original (Fiksel, 2003; Folke, 2006; Manyena, 2006) }\end{array}$ \\
\hline $\begin{array}{l}\text { Stance on the nature } \\
\text { of disturbances }\end{array}$ & $\begin{array}{l}\text { Disturbance is external with linear and proportional cause/ } \\
\text { effect ratio (Davoudi et al., 2012) }\end{array}$ & $\begin{array}{l}\text { Disturbance is external with linear and proportional cause/ } \\
\text { effect ratio (Davoudi et al., 2012; Ford 2009; Barthel and } \\
\text { Isendahl 2013) }\end{array}$ \\
\hline Key attributes & $\begin{array}{l}\text { Return time, efficiency, constancy and predictability (King, } \\
\text { 2008) }\end{array}$ & $\begin{array}{l}\text { Thresholds of disturbance that will lead to new system. } \\
\text { Persistence and adaptability (Folke, 2006; King, 2008; Lebel } \\
\text { et al., 2006; Redman, 2014) }\end{array}$ \\
\hline
\end{tabular}


Table IV Categorisation of reviewed literature by resilience definition

\section{Food}

Specificity

\section{Context}

Author

Definition

Engineering Ecological Adaptive

\section{Food}

Specific
Milestad and Darnhofer (2003)

Smith et al. (2016)

Tendall et al. (2015)

Sinclair et al. (2014)

Macfadyen et al. (2015)

King (2008)

Supply Chain Management

\author{
Carvalho et al. (2012a, \\ 2012b)
}

Ivanov et al. (2015)

Yang and Xu (2015)

Fałkowski (2015)

Leat and RevoredoGiha (2013)

Manning and Soon (2016)

Organisational Higgins et al. (2010) Management
"The magnitude of disturbance that can be experienced before a system moves into a different state with different sets of controls"

"The existence, development, and engagement of community resources by community members to thrive in an environment characterised by change, uncertainty, unpredictability, and surprise and to develop new trajectories for the community's future" "Capacity over time of a food system and its units at multiple levels, to provide sufficient, appropriate and accessible food to all, in the face of various and even unforeseen disturbance"

"The capacity of a system to absorb disturbance and reorganise so as to retain essentially the same function, structure, identity and feedbacks"

"Here we talk about resilience in terms of production variability and the ability of agro-ecosystems to maintain stability in production levels even in the face of disturbances"

"A system's ability to adapt and respond to external impacts on a system"

"Supply Chain resilience is concerned with the system's ability to return to its original state or to a new, more desirable, one, after experiencing a disturbance, and avoiding the occurrence of failure modes"

"Resilience refers to the capacity of organizations or

$X$ systems to return to full functionality in the face of disruption"

"The ability of a system to return to its original state or move to a new and more desirable state after being disturbed, or to adapt existing resources and skills to new situations and operating conditions, in order to survive despite withstanding a severe and enduring impact"

"The term "resilience" refers to the ability of a system to maintain output close to potential in the aftermath of shocks or, alternatively, the ability of a system to return to its original state after being disturbed"

"Resilience aims at developing the adaptive capability of the chain to prepare for unexpected events and to respond to disruptions and recover from them"

"Strategic resilience is not about responding to a single crisis or rebounding from a setback, it encompasses anticipating and reacting to secular trends that can permanently impair the earning power of the core business"

"Resilience is the capacity of a system to recover from disturbance and maintain its structure function and controls with the human element of socioecological systems able to proactively avoid or benefit from such disturbances" 
Table IV

\section{Food}

Specificity?

Non-Food

Specific

$\begin{array}{ll}\text { Social Systems } & \text { Milman and Short } \\ (2008)\end{array}$

Ponomarov and

Holcomb (2009)

Manyena (2006)

Davoudi et al. (2012)

Rose (2011)

McDaniels et al. (2008)

Ecological Derissen et al. (2011)

Systems

Fiksel (2003)

Tukamuhabwa et al.

Lebel et al. (2006)

Redman (2014)

Folke (2006)

Supply Chain Management

Colicchia et al. (2010)

Carvalho et al. (2012a, 2012b)
Definition

Engineering Ecological Adaptive

"Resilience includes more than maintaining given

system characteristics; it includes the adaptive

capacity of the system -its ability to adapt to

stresses and changes and to transform into more desirable states"

"The adaptive capability of the supply chain to prepare

for unexpected events, respond to disruptions and recover from them by maintaining continuity of operations at the desired level of connectedness and control over structure and function"

"Resilience could be viewed as the intrinsic capacity of a system, community or society predisposed to a shock or stress to adapt and survive by changing its non-essential attributes and rebuilding itself"

"Resilience is not conceived of as a return to normality, but rather as the ability of complex socio-ecological systems to change, adapt, and, crucially, transform in response to stresses and strains"

"The ability of a system to maintain function when shocked and to hasten the speed of recovery from a shock"

"A complex system's capacity to absorb shocks while maintaining function. Enhanced by both risk mitigation activities undertaken before the disaster and response activities following the event"

"The magnitude of disturbance that can be absorbed before the system changes its structure by changing the variables and processes that control behaviour" "Resilience can be defined as the capacity of a system to tolerate disturbances whilst retaining its structure and function"

"The adaptive capability of a supply chain to prepare for and/or respond to disruptions, to make a timely and cost effective recovery, and therefore progress to a post-disruption state of operations - ideally, a better state than prior to the disruption"

"Resilience is a measure of the amount of change a system can undergo and still retain the same controls on structure and function or remain in the same domain of attraction"

"Resilience is the capacity of a system to experience shocks while retaining function, structure, feedback capabilities, and therefore identity"

"The capacity of the system 'to absorb disturbance and re-organise while undergoing change so as to still retain essentially the same function, structure, identity, and feedbacks"

"The ability of a system to quickly react to the undesired events when they happen"

"Resilience refers to the ability of the supply chain to cope with unexpected disturbances. It is concerned with the system ability to return to its original state or to a new one, more desirable, after experiencing a disturbance, and avoiding the occurrence of failure modes" 
Table IV

\begin{tabular}{ll}
\hline $\begin{array}{l}\text { Food } \\
\text { Specificity? }\end{array}$ & Context \\
\hline & Todo et al. (2015) \\
& Kamalahmadi and \\
& Parast (2016)
\end{tabular}

Pereira et al. (2014)

Pettit et al.(2008)

Elleuch et al. (2016a 2016b)

Wang et al. (2016)

Brandon-Jones et al. (2014)

Peck (2005)

Ambulkar et al. (2015)

Jüttner and Maklan. (2011)

Christopher and Peck (2004)

\section{Organisational Asbjornslett et al.} (1999)

Fahimnia and Jabbarzadeh (2016)

Kim et al. (2015)
"Defined as speedy recovery through the repair and Engineering Ecological Adaptive reconstruction of capital stock"

"We define Firm/Enterprise Resilience as "the dynamic capability of an enterprise, which is highly dependent on its individuals, groups, and subsystems, to face immediate and unexpected changes in the environment with proactive attitude and thought, and adapt and respond to these changes by developing flexible and innovative solutions"

"Supply chain resilience is defined here as the capability of supply chains to respond quickly to unexpected events so as to restore operations to the previous performance level or even to a new and better one"

"The capacity for an enterprise to survive, adapt and $x$ grow in the face of turbulent change"

X

"In this context, resilience is defined as the ability of

$X$ a system to return to its original state or a more favourable condition, after being disturbed"

"A resilient system is a system with an objective to survive and maintain function even during the course of disruptions, provided with a capability to predict and assess the damage of possible disruptions, and enhanced by the strong awareness of its ever-changing environment and knowledge of the past events, thereby utilizing resilient strategies for defence against the disruptions"

"We define supply chain resilience as the ability of a supply chain to return to normal operating performance, within an acceptable period of time, after being disturbed"

"The ability of a system to return to its original [or desired] state after being disturbed"

"Firm's resilience to supply chain disruptions is defined as the capability of the firm to be alert to, adapt to, and quickly respond to changes brought by a supply chain disruption"

"Supply chain resilience addresses the supply chain's ability to cope with the consequences of unavoidable risk events in order to return to its original operations or move to a new, more desirable state after being disturbed"

"The ability of a system to return to its original state or move to a new, more desirable state after being disturbed"

"Resilience may be defined as a system's ability to return to a new stable situation after an accidental event"

"The capacity of a SC to absorb disturbances and retain its basic function and structure in the face of disruptions"
X

X 
Table IV

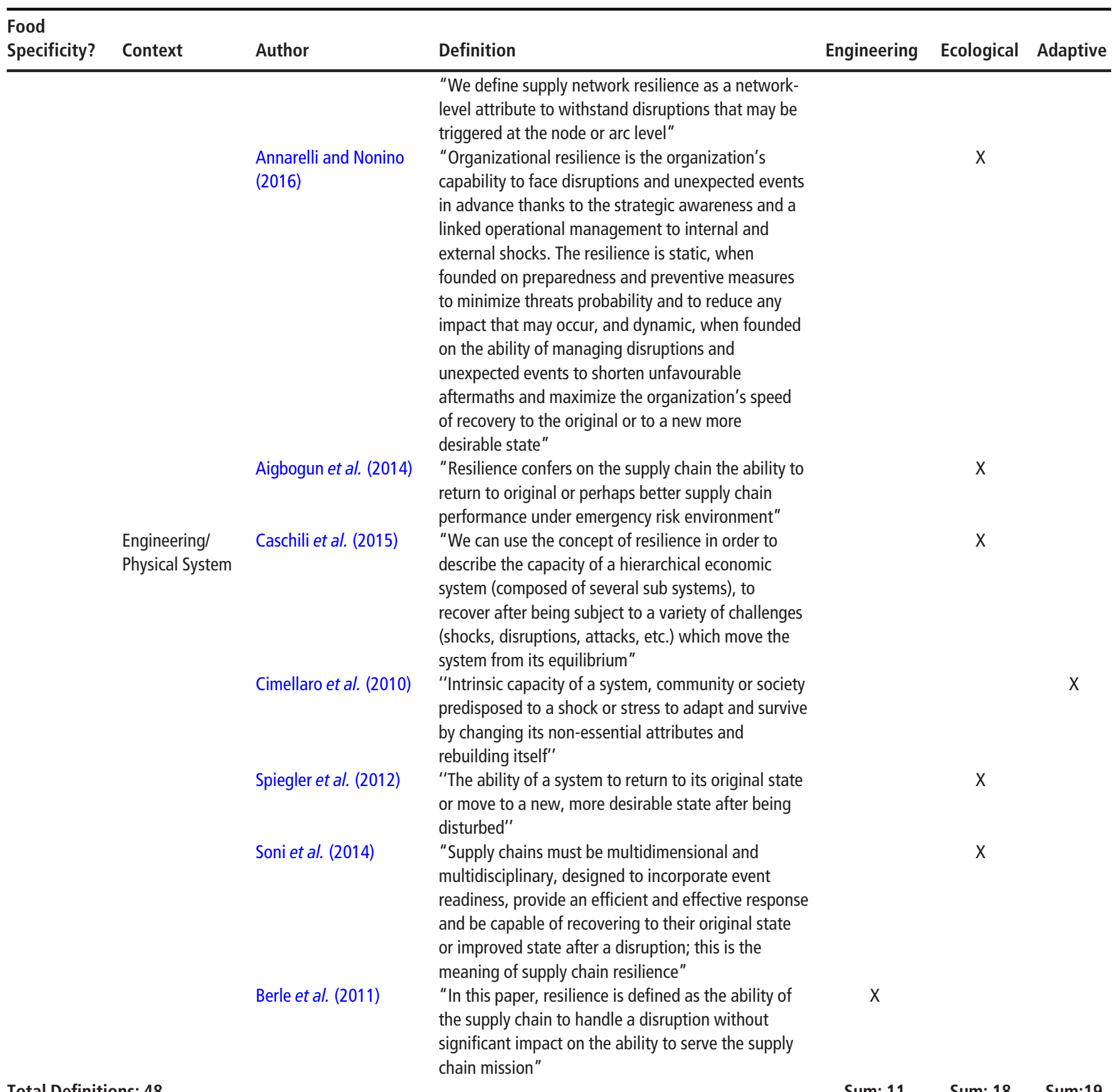

Total Definitions: 48

A breakdown in any one of these areas can lead to harvests failing, transport links breaking and consumer demands and tastes changing (Milman and Short, 2008; Yang and $\mathrm{Xu}$, 2015). Therefore logically, to be resilient in such a world is to prioritise constant adaptation and reorganisation. As such, the complexity of vulnerability sources is much broader than an individual organisation might consider from a risk management perspective, and this would explain the observed preference for the adaptive definition. Key features of adaptive food definitions included the ability to maintain "function" as well as the ability of systems to adapt rather than to return to existing states of equilibrium. Tendall et al. (2015) advance the field by linking "function" with the United Nations Food and Agricultural Organisation definition of food security which concerns the four pillars of availability, access, utilisation and stability of food to end consumers (Fao, 2012; Tendall et al., 2015).

In comparison, non-AFSC-specific works saw greater contribution from organisational management and engineering/physical systems approaches. In these contexts, 
resilience consideration often takes place within an enclosed system, for example, a factory, and vulnerabilities tend to be more controllable and predictable (for example, machine faults, staff illness, etc.), thus encouraging pursuit of a single optimal management strategy (Vlajic et al., 2013; Berle et al., 2011). This can be seen as analogous to a "state of equilibrium" and would explain the preference in such works for an ecological definition of resilience where the focus is on a particular organisation's competitive advantage, specifically, minimising the time and cost of a disruption and exploiting competitor weaknesses (Pereira et al., 2014; Kim et al., 2015; Todo et al., 2015).

Articles in the area of SCM, regardless of whether they are AFSC focussed or not, have shown a growing shift away from engineering definitions of resilience towards adaptive definitions in recent years. There is evidence that this transition is linked to increasing awareness of the importance of constantly changing operating environments, in particular, the evolving challenges and opportunities of outsourcing to lowcost countries (Tang and Musa, 2011).

Moving forward, a number of definitions in Table IV refer to one or more of the following abilities: to "Resist", to "Recover" and/or "Adapt"(Soni et al., 2014; Fahimnia and Jabbarzadeh, 2016; Leat and Revoredo-Giha, 2013; Annarelli and Nonino, 2016). Ponomarov and Holcomb (2009) categorised these into the distinct phases of readiness, response and recovery. Readiness refers to an organisation's ability to anticipate disruption and either prepare for it or avoid it. Response refers to either innate or pre-planned elements that mitigate the impact of a disruption, as it happens. Recovery refers to the ability of an organisation to repair losses caused by a disruption and return to meeting core priorities. Hohenstein et al. (2015) add the fourth phase of "Growth" which concerns learning from and adapting core priorities post disruption so that competitiveness actually improves compared to pre-disruption levels. However, it has been noted that many articles overwhelmingly see disruption in light of the reactive and recovery phases only (Higgins et al., 2010; Hohenstein et al., 2015).

Therefore, to summarise findings in relation to review Q1.1, it has been identified that resilience of AFSCs is frequently equated with the ability not only to resist disruption but also particularly to maintain the core function of supplying food to end consumers. The priority of resilience in AFSCs can therefore be described as the food security of end consumers. AFSCs are also incredibly complex systems involving myriad bio-geophysical, social, economic and political drivers and feedbacks that must be managed holistically to enhance resilience. Therefore, any definition of AFSC resilience must include the ability to adapt in line with changing operating environments as well as to prioritise availability, access, suitability and stability of food supply. To do so, it must consider more than the traditional phases of resisting and recovering from disruption and also include anticipation and post-disruption learning. Therefore, the authors of this paper propose the following definition of AFSC resilience:

The collective ability of Agri-food supply chain stakeholders to ensure acceptable, sufficient and stable food supplies, at the required times and locations, via accurate anticipation of disruptions and the use of strategies which delay impact, aid rapid recovery and allow cumulative learning postdisruption.
This definition builds on existing adaptive definitions of foodrelated resilience by incorporating the priority of food security rather than individual organisational competitiveness. By nature, it implies that resilience strategies must consider how resilience strategies implemented by one actor impact overall SCRES. Furthermore, by incorporating the fourth food security pillar of stability, the synergistic relationship between resilience and sustainability is highlighted.

A key component of this definition is the word "mechanisms" and to explore what this practically entails; this review now moves on to Q1.2 to identify AFSC relevant resilience "elements" and "strategies".

\subsection{Addressing Q1.2}

There have been a number of works which propose strategies for manipulating an actor's resilience, many of which fall within the SCM discipline. Such strategies frequently rely on the assumption that resilience can be controlled by a portfolio of variously named "antecedents", "attributes", "capabilities", "elements" and "enhancers" which are management tools to counteract specific vulnerabilities (Hohenstein et al., 2015; Pettit et al., 2010; Pereira et al., 2014; Kamalahmadi and Parast, 2016). For consistency, and in line with Christopher and Peck (2004), Hohenstein et al. (2015) and Kamalahmadi and Parast (2016), the term "elements" is used from now onwards.

In total, 61 articles proposed one or more key elements for resilience. From these, this review identified 40 unique resilience elements. This breadth of resilience elements has, to the author's knowledge, not been attempted previously in the literature. These elements varied significantly in terms of "scope". This refers to whether resilience elements were applicable in response to disruptions within an individual organisation (for example, machinery faults) or within a supply chain (for example, loss of a specific supplier), in which case, elements addressed ways in which the supply chain could collectively adapt. The list of identified elements and their respective scope and publication sources are given in Table $\mathrm{V}$. It should be noted that some elements appear in both the intraorganisational and intra-supply chain columns albeit with different contexts. For example, redundancy at an organisational level refers to spare capacity and inventory, but at a supply chain level describes alternative transport routes between stages or backup infrastructure. When ranked according to the number of papers mentioning a specific element, flexibility, risk aware culture, redundancy and early warning detection systems were the most commonly cited elements at an organisational level. At a supply chain level, collaboration, flexibility, agility, visibility and adaptability were, respectively, the most commonly cited elements.

Despite there being a number of highly cited resilience elements, the overwhelming majority of elements identified appeared in less than 10 per cent of papers reviewed. This suggests that there is poor consensus on what elements are the most important for resilience. For example, Fiksel (2003) proposes four elements: diversity, efficiency, adaptability and cohesion. Pettit et al. (2010) on the other hand identifies 14 different elements. Without empirical validation, it is difficult to be sure that just because a resilience element is cited more frequently, that it is more significant for resilience than a less 
Table V Survey of resilience elements from the literature

\begin{tabular}{|c|c|c|c|c|c|}
\hline Scope & Capability & Details & $\begin{array}{l}\text { No. } \\
\text { Papers }\end{array}$ & $(\%)$ & Sources \\
\hline \multirow[t]{10}{*}{$\begin{array}{l}\text { Intra- } \\
\text { Organisational (IO) }\end{array}$} & IO 1. Flexibility & $\begin{array}{l}\text { Ability of an organisation to adapt with } \\
\text { minimum time and effort. } \\
\text { Concerns the ability to switch suppliers, } \\
\text { substitute ingredients, outsource } \\
\text { processes, share materials and staff } \\
\text { between sites, the ability of staff to fulfil } \\
\text { multiple roles (I015) and the levels of } \\
\text { control over market position (I016) }\end{array}$ & 9 & 14.75 & $\begin{array}{l}\text { Tukamuhabwa et al. (2015), } \\
\text { Kamalahmadi and Parast (2016), Pal et } \\
\text { al. (2014), Stecke and Kumar (2009), } \\
\text { Pettit et al. (2010), Tang (2006), Tomlin } \\
\text { (2006), Zsidisim and Wagner (2010), } \\
\text { Carvalho et al. (2012a, 2012b) }\end{array}$ \\
\hline & $\begin{array}{l}\text { I0 2. Risk Aware } \\
\text { Culture }\end{array}$ & $\begin{array}{l}\text { Describes the infrastructure a firm has in } \\
\text { place to manage risk. } \\
\text { For example this could include efficiency } \\
\text { standards (IO4) such as six sigma, and } \\
\text { the presence of Business Continuity } \\
\text { (I013) and Enterprise Risk Management } \\
\text { Programmes }\end{array}$ & 9 & 14.75 & $\begin{array}{l}\text { Christopher and Lee (2004), Blome and } \\
\text { Schoenherr (2011), Jüttner and Maklan. } \\
\text { (2011), Gölgeci and Ponomarov (2015), } \\
\text { Ritchie and Brindley (2007), Peck } \\
\text { (2005), Scholten et al. (2014), Thun and } \\
\text { Hoenig (2011), Neureuther and Kenyon } \\
\text { (2009) }\end{array}$ \\
\hline & I0 3. Redundancy & $\begin{array}{l}\text { Concerns the ability to alternate } \\
\text { production capacity and to call upon } \\
\text { surplus raw materials and finished } \\
\text { inventory }\end{array}$ & 8 & 13.11 & $\begin{array}{l}\text { Tukamuhabwa et al. (2015), Ponis and } \\
\text { Koronis (2012), Manuj and Mentzer } \\
\text { (2008), Stecke and Kumar (2009), } \\
\text { Wieland and Wallenburg (2013), } \\
\text { Aigbogun et al. (2014), Carvalho et al. } \\
\text { (2012b), McKinnon (2006) }\end{array}$ \\
\hline & $\begin{array}{l}\text { I0 4. Early Warning } \\
\text { Detection Systems }\end{array}$ & $\begin{array}{l}\text { This concerns the use of foresight to } \\
\text { extend preparation time. } \\
\text { Specifically, it can include intelligence } \\
\text { generation through big data and the } \\
\text { internet of things }\end{array}$ & 5 & 8.1 & $\begin{array}{l}\text { Suweis et al. (2015), Christopher and } \\
\text { Peck (2004), Stecke and Kumar (2009), } \\
\text { Gunasekaran et al. (2011), Pettit et al. } \\
\text { (2010) }\end{array}$ \\
\hline & IO 5. Security & $\begin{array}{l}\text { This refers to the security of both } \\
\text { electronic information and the physical } \\
\text { security of assets }\end{array}$ & 4 & 6.5 & $\begin{array}{l}\text { Pettit et al. (2010), Stecke and Kumar } \\
\text { (2009), Faisal and Banwet (2006), } \\
\text { Elleuch et al. (2016a, 2016b) }\end{array}$ \\
\hline & IO 6. Efficiency & $\begin{array}{l}\text { The way in which resources are used so } \\
\text { as to avoid unnecessary waste and } \\
\text { disruption. } \\
\text { This could refer to the presence of } \\
\text { efficiency standards such as six sigma }\end{array}$ & 4 & 6.5 & $\begin{array}{l}\text { Fiksel (2003), Pettit et al. (2010), } \\
\text { Aramyan et al. (2007), Elleuch et al. } \\
\text { (2016a, 2016b) }\end{array}$ \\
\hline & $\begin{array}{l}\text { I0 7. Contingency } \\
\text { Plans }\end{array}$ & $\begin{array}{l}\text { Pre-established crisis management } \\
\text { teams and procedural guides for } \\
\text { potential disruptions to enhance } \\
\text { response speed and effectiveness. } \\
\text { Most effective when combined with } \\
\text { "I04 Early Warning Detection Systems" }\end{array}$ & 3 & 4.9 & $\begin{array}{l}\text { Zsidisin et al. (2010), Jüttner and } \\
\text { Maklan (2011), Dani and Deep (2010) }\end{array}$ \\
\hline & $\begin{array}{l}\text { I0 8. Inventory } \\
\text { Management }\end{array}$ & $\begin{array}{l}\text { Increased visibility of supplier } \\
\text { operations and transport mediums to } \\
\text { reduce the amount of redundancy } \\
\text { required in a disruption. } \\
\text { Closely related to "IS4 Visibility" }\end{array}$ & 3 & 4.9 & $\begin{array}{l}\text { Kleindorfer et al. (2005), Wu et al. } \\
\text { (2013), Stecke and Kumar (2009) }\end{array}$ \\
\hline & $\begin{array}{l}\text { I0 9. Financial } \\
\text { Strength }\end{array}$ & $\begin{array}{l}\text { Availability of easily accessible financial } \\
\text { assets. Linked to "I01 Flexibility" }\end{array}$ & 3 & 4.9 & $\begin{array}{l}\text { Pettit et al. (2010), Pereira et al. (2014), } \\
\text { Dani and Deep (2010) }\end{array}$ \\
\hline & $\begin{array}{l}\text { I0 10. Leadership } \\
\text { Commitment }\end{array}$ & $\begin{array}{l}\text { This concerns the quality of leadership } \\
\text { and how it interacts with the rest of an }\end{array}$ & 3 & 4.9 & $\begin{array}{l}\text { Durach et al. (2015), Kamalahmadi and } \\
\text { Parast (2016), Dani and Deep (2010) }\end{array}$ \\
\hline
\end{tabular}

organisation.

It might concern the ability to prioritise, inspire and to learn from others/past disruptions. 


\begin{tabular}{|c|c|c|c|c|c|}
\hline Scope & Capability & Details & $\begin{array}{l}\text { No. } \\
\text { Papers }\end{array}$ & $(\%)$ & Sources \\
\hline & & $\begin{array}{l}\text { Important in establishing effective risk } \\
\text { management culture }\end{array}$ & & & \\
\hline & I0 11. Relationships & $\begin{array}{l}\text { The way in which different teams and } \\
\text { departments interact. } \\
\text { Important aspects include } \\
\text { communication methods and the routes } \\
\text { of information flow }\end{array}$ & 3 & 4.9 & $\begin{array}{l}\text { Smith et al. (2016), Durach et al. (2015), } \\
\text { Christopher and Lee (2004) }\end{array}$ \\
\hline & $\begin{array}{l}\text { I0 12. Human } \\
\text { Resource } \\
\text { Management }\end{array}$ & $\begin{array}{l}\text { This concerns the ways in which human } \\
\text { assets are trained, retained and allowed } \\
\text { to develop. } \\
\text { Examples include skillsets generated } \\
\text { (particularly ability to fulfil multiple } \\
\text { roles) and the use of staff in identifying } \\
\text { risk }\end{array}$ & 2 & 3.2 & $\begin{array}{l}\text { Durach et al. (2015), Stecke and Kumar } \\
\text { (2009) }\end{array}$ \\
\hline & $\begin{array}{l}\text { I0 13. Business } \\
\text { Continuity }\end{array}$ & $\begin{array}{l}\text { Contingency planning for the protection } \\
\text { of "mission critical assets". } \\
\text { Key component of "IS10 Robustness" }\end{array}$ & 2 & 3.2 & Peck (2005), Suweis et al. (2015) \\
\hline & I0 14. Innovation & $\begin{array}{l}\text { Presence of shared beliefs, openness to } \\
\text { learning and joint decision-making }\end{array}$ & 2 & 3.2 & $\begin{array}{l}\text { Kamalahmadi and Parast (2016), } \\
\text { Gölgeci and Ponomarov (2015) }\end{array}$ \\
\hline & $\begin{array}{l}\text { IO 15. Knowledge } \\
\text { Management }\end{array}$ & $\begin{array}{l}\text { Staff skills and knowledge retention that } \\
\text { effect their ability to change pace and } \\
\text { type of role in a disruption. } \\
\text { Sometimes cited as a component of "I01 } \\
\text { Flexibility" }\end{array}$ & 2 & 3.2 & $\begin{array}{l}\text { Scholten et al. (2014), Pereira et al. } \\
\text { (2014) }\end{array}$ \\
\hline & $\begin{array}{l}\text { I0 16. Market } \\
\text { Position }\end{array}$ & $\begin{array}{l}\text { Factors such as market share, product } \\
\text { differentiation and customer } \\
\text { communications which can be } \\
\text { manipulated to aid recovery in the event } \\
\text { of a disruption. } \\
\text { An aspect of "I01 Flexibility" }\end{array}$ & 1 & 1.6 & Pettit et al. (2010) \\
\hline & $\begin{array}{l}\text { I0 17. Adaptive } \\
\text { Management }\end{array}$ & $\begin{array}{l}\text { Active monitoring of decisions made in } \\
\text { relation to past disruptions and their } \\
\text { outcomes for incremental learning }\end{array}$ & 1 & 1.6 & Milestad and Darnhofer (2003) \\
\hline \multirow[t]{2}{*}{$\begin{array}{l}\text { Intra-Supply Chain } \\
\text { (IS) }\end{array}$} & IS 1. Collaboration & $\begin{array}{l}\text { Refers to two or more actors working } \\
\text { together to generate advantages that } \\
\text { could not be achieved individually. This } \\
\text { could be in the form of: } \\
\text { Shared forecasting, postponement and } \\
\text { risk sharing. } \\
\text { Cooperation and partnership. } \\
\text { Aim of reducing uncertainties and } \\
\text { complexity. } \\
\text { Integration of systems }\end{array}$ & 19 & 31.1 & $\begin{array}{l}\text { Jüttner et al. (2011), Pettit et al. (2010), } \\
\text { Christopher and Peck. (2004), Carvalho } \\
\text { et al. (2014), Scholten et al. (2014), } \\
\text { Barratt et al. (2004), Zacharia et al. } \\
\text { (2009), Smith et al. (2016), Hohenstein } \\
\text { et al. (2015), Tukamuhabwa et al. } \\
\text { (2015), Kamalahmadi and Parast (2016), } \\
\text { Gunasekaran et al. (2011), Chen et al. } \\
\text { (2012), Giannakis and Louis (2011), } \\
\text { Johnson et al. (2013), Habermann et al. } \\
\text { (2015), Lee. (2014), Dani and Deep } \\
\text { (2010), Elleuch et al. (2016a, 2016b) }\end{array}$ \\
\hline & IS 2. Flexibility & $\begin{array}{l}\text { Degree by which a supply chain can } \\
\text { respond to changing operating } \\
\text { environments and customer requests. } \\
\text { Supply chain wide alternative options } \\
\text { achieved through partnerships. } \\
\text { Ability to move staff and equipment } \\
\text { rapidly }\end{array}$ & 18 & 29.5 & $\begin{array}{l}\text { Lam and Bai (2016), Natarajarathinam et } \\
\text { al. (2009), Pettit et al. (2013), Tendall et } \\
\text { al. (2015), Estrada-Flores et al. (2009), } \\
\text { Stecke and Kumar (2009), Ivanov et al. } \\
\text { (2015), Jüttner et al. (2011), Durach et al. } \\
\text { (2015), Suweis et al. (2015), Soni et al. } \\
\text { (2014), Skipper et al. (2009), Smith et al. } \\
\text { (2016), Swafford et al. (2006), Stevenson } \\
\text { and Spring (2007), Gligor and Holcomb. } \\
\text { (2012), Aramyan et al. (2007) }\end{array}$ \\
\hline
\end{tabular}




\begin{tabular}{|c|c|c|}
\hline Scope & Capability & Details \\
\hline & IS 3. Agility & $\begin{array}{l}\text { The ability to respond quickly to } \\
\text { unpredictable changes in supply and } \\
\text { demand by changing configuration at } \\
\text { tactical level. } \\
\text { Examples include logistics capabilities } \\
\text { and manufacturing flexibility }\end{array}$ \\
\hline
\end{tabular}

IS 4. Visibility

IS 5. Adaptability

IS 7.Information

flow

IS 8. Velocity

IS 10. Robustness and products from one end of the supply chain to the other.

Includes factors that aid availability of information such as channels for the sharing of risk information and IT infrastructure as well as frameworks guiding how this information is delivered to the right people at the right time

The ability of a system to adapt incrementally or to completely transform in response to a changing operating environment

Exists when a single entity within a supply chain is depended upon by a disproportionately large number of other entities, for example, a key port facility.

Can significantly influence "IS2

Flexibility"

Refers to the efficiency and effectiveness of information flow.

Key determinant of "IS1 Collaboration"

Speed at which products reach end

consumer.

Specific examples include efficiency, reduction of lead times and synchronisation of schedules. Element of "IS3 Agility"

Concerns the system wide design of emergency back-up and storage facilities, surplus pathways between nodes and the extent to which elements are replaceable

Concerns the ability of a system to withstand a given amount of stress without loss of function
The ability to see structures, processes

No.

Papers (\%) Sources

17

27.8

Christopher and Peck (2004), Wieland and Wallenburg (2013), Durach et al. (2015), Braunscheidel and Suresh (2009), Swafford et al. (2006), Durach et al. (2015), Tendall et al. (2015), Sharifi and Zhang (1999), Hohenstein et al. (2015), Tukamuhabwa et al. (2015), Kamalahmadi and Parast (2016), Gligor and Holcomb (2012), Pereira et al. (2014), Scholten et al. (2014), Aramyan et al. (2007), Johnson (2013), Dubey et al (2014), Sharifi and Zhang (1999)

15 24.5 Christopher and Lee (2004), Pettit et Carvalho et al. (2014, Soni (2014), Gunasekaran (2004), Smith et al. (2016), Durach et al. (2015), Faisal and Banwet (2006), Kamalahmadi and Parast (2016), Pereira et al. (2014), Stecke and Kumar (2009), Gunasekaran et al. (2011), Aigbogun et al. (2014), Johnson et al. (2013)

$9 \quad 14.75 \quad$ Fiksel (2003), King (2008), Tukamuhabwa et al. (2015), Pettit. (2010), Sinclair et al. (2014), EstradaFlores et al. (2009), Milestad and Darnhofer (2003), Lebel et al. (2006) Tendall et al. (2015)

$6 \quad 9.8$ Durach et al. (2015), Kamalahmadi and Parast (2016), Stecke and Kumar (2009), Aigbogun et al. (2014), Ratick et al. (2008), Fraser et al. (2005)

Smith et al. (2016), Kamalahmadi and Parast (2016), Christopher and Peck (2004), Soni et al. (2014), Pereira et al. (2014), Faisal and Banwet (2006) Carvalho et al. (2014), Jüttner et al. (2011), Christopher and Peck (2004), Kamalahmadi and Parast (2016), Pereira et al. (2014), Johnson et al. (2013)

6

Spiegler et al. (2012), Ivanov et al. (2015), Milestad and Darnhofer (2003), Bode et al. (2011), Ratick et al. (2008), Fiksel (2003)

6 9.8
McDaniels et al. (2008), Bruneau et al. (2003), Tendall et al. (2015), Ivanov et al. (2015), Rodriguez-Nikl (2015), Wieland and Wallenburg (2013) 


\begin{tabular}{|c|c|c|c|c|c|}
\hline Scope & Capability & Details & $\begin{array}{l}\text { No. } \\
\text { Papers }\end{array}$ & (\%) & Sources \\
\hline & $\begin{array}{l}\text { IS 11. Self- } \\
\text { organisation }\end{array}$ & $\begin{array}{l}\text { Concerns the autonomy, ability and will } \\
\text { of a system to internally organise itself } \\
\text { as opposed to being completely at the } \\
\text { whim of external forces }\end{array}$ & 4 & 6.5 & $\begin{array}{l}\text { Milestad and Darnhofer (2003), Estrada- } \\
\text { Flores et al. (2009), Lebel et al. (2006), } \\
\text { Pettit et al. (2010) }\end{array}$ \\
\hline & IS 12. Rapidity & $\begin{array}{l}\text { Capacity to meet priorities and achieve } \\
\text { goals in a timely manner to contain } \\
\text { losses and avoid future disruption }\end{array}$ & 4 & 6.5 & $\begin{array}{l}\text { Rodriguez-Nikl (2015), McDaniels et al. } \\
\text { (2008), Tendall et al. (2015), Bruneau et } \\
\text { al. (2003) }\end{array}$ \\
\hline & $\begin{array}{l}\text { IS 13. Established } \\
\text { Communication } \\
\text { Lines }\end{array}$ & $\begin{array}{l}\text { Pre-planned communication } \\
\text { infrastructure and protocols that aid } \\
\text { response speed and effectiveness in a } \\
\text { disruption situation }\end{array}$ & 4 & 6.5 & $\begin{array}{l}\text { Suweis et al. (2015), Hohenstein et al. } \\
\text { (2015), Stecke and Kumar (2009), Dani } \\
\text { and Deep (2010) }\end{array}$ \\
\hline & 1S 14. Trust & $\begin{array}{l}\text { Refers to the presence of enough trust } \\
\text { between system actors that problems } \\
\text { can be discussed openly. } \\
\text { Key determinant of "IS1 Collaboration" }\end{array}$ & 3 & 4.9 & $\begin{array}{l}\text { Kamalahmadi and Parast (2016), Pereira } \\
\text { et al. (2014), Faisal and Banwet (2006) }\end{array}$ \\
\hline & $\begin{array}{l}\text { IS } 15 . \text { Risk } \\
\text { Management } \\
\text { Orientation }\end{array}$ & $\begin{array}{l}\text { Presence of risk management strategies } \\
\text { throughout operations of all supply } \\
\text { chain partners. } \\
\text { Can significantly reduce recovery time } \\
\text { and cost post-disruption }\end{array}$ & 2 & 3.2 & $\begin{array}{l}\text { Durach et al. (2015), Jüttner et al. } \\
\text { (2011) }\end{array}$ \\
\hline & IS 16. Diversity & $\begin{array}{l}\text { Refers to variety in inputs, suppliers, } \\
\text { staff and customers and important in } \\
\text { the generation of system wide } \\
\text { redundancy }\end{array}$ & 2 & 3.2 & $\begin{array}{l}\text { Fiksel (2003), Carvalho et al. (2012a, } \\
\text { 2012b), }\end{array}$ \\
\hline & IS 17. Cohesion & $\begin{array}{l}\text { The existence of unifying factors } \\
\text { between supply chain organisations, } \\
\text { such as mutual end consumers, that can } \\
\text { drive collaboration }\end{array}$ & 2 & 3.2 & $\begin{array}{l}\text { Fiksel (2003), Carvalho et al. (2012a, } \\
\text { 2012b), }\end{array}$ \\
\hline & $\begin{array}{l}\text { IS 18. Network } \\
\text { Complexity }\end{array}$ & $\begin{array}{l}\text { Refers to the number of nodes and } \\
\text { length between them in a supply chain. } \\
\text { Can effect rerouting options and } \\
\text { communication times in a disruption }\end{array}$ & 2 & 3.2 & Durach et al. (2015), Pettit et al. (2010) \\
\hline & IS 19. Co-Learning & $\begin{array}{l}\text { This refers to the systems in place to aid } \\
\text { supply chain wide joint learning from } \\
\text { both near misses and actual disruptions }\end{array}$ & 2 & 3.2 & King (2008), Lebel et al. (2006) \\
\hline & $\begin{array}{l}\text { IS 20. Bargaining } \\
\text { Power }\end{array}$ & $\begin{array}{l}\text { The presence of factors such as } \\
\text { significant vertical integration that can } \\
\text { influence the ability of other entities to } \\
\text { act in a resilient manor }\end{array}$ & 1 & 1.6 & Durach et al. (2015) \\
\hline & $\begin{array}{l}\text { IS } 21 . \text { Community } \\
\text { resources }\end{array}$ & $\begin{array}{l}\text { The range of ecological, economic, } \\
\text { social, physical, institutional and } \\
\text { cultural resources a community can } \\
\text { draw upon when faced with disruption }\end{array}$ & 1 & 1.6 & Smith et al. (2016) \\
\hline & $\begin{array}{l}\text { IS } 22 . \\
\text { Responsiveness }\end{array}$ & $\begin{array}{l}\text { Supply chain responsiveness to } \\
\text { customers, for example, the ability to } \\
\text { drive down lead times }\end{array}$ & 1 & 1.6 & Aramyan et al. (2007) \\
\hline & $\begin{array}{l}\text { IS 23. Buffer } \\
\text { capacity }\end{array}$ & $\begin{array}{l}\text { Concerns the amount of change a } \\
\text { system can undergo while retaining core } \\
\text { functions. } \\
\text { Major similarities with "IS10 } \\
\text { Robustness" }\end{array}$ & 1 & 1.6 & Milestad and Darnhofer (2003) \\
\hline
\end{tabular}


commonly cited capability. In particular, many of the less commonly cited elements are from research fields that are less active in the area of resilience, such as ecological and social systems. Such elements concern interactions and relations between organisations, communities and the natural environment as well as their ability to adapt, which are of major significance to "adaptive resilience" in AFSCs. Therefore, there is a need to capture the relationship between such elements and the more commonly cited elements.

The authors of this review identified that of the 40 resilience elements, some were broad in scope and some were much narrower, referring to specific aspects of the broader elements. These are referred to as "Core" and "Supporting" elements, respectively. For example, at a supply chain level, the authors of this review propose that flexibility is a "Core" resilience element, concerning supply chain wide alternative options of responding to a disruption. The resilience elements of "I016 Knowledge Management" and "IO16 Market Position" for example, while enabling resilience in their own right, are often cited as aspects of "IO1 Flexibility" (Carvalho et al., 2012a, 2012b; Pettit et al., 2010; Tomlin, 2006). Therefore, while IO15 and IO16 are not duplicates of IO1, they can be seen as "Supporting" resilience elements. This novel method of categorising resilience elements of relevance to AFSCs is shown in Figure 6. Categorising resilience elements in this way is useful for application to AFSCs because elements that represent communities and ecosystem services can be more easily recognised as supporters of more commonly cited elements. The proposed "Core" elements at an organisational level are now described in more detail.

\subsubsection{Proposed "core" intra-organisational resilience elements}

3.3.1.1 Intra-organisational 1: flexibility. At an organisational perspective, flexibility was cited in 14.75 per cent of articles reviewed. For most organisations, there will be two broad areas in which flexibility can be implemented; at sourcing and at production and distribution (Pettit et al., 2010). At sourcing, flexibility concerns ability to quickly change inputs (or mode of receiving inputs) through utilisation of common product platforms, product modularity, multiple pathways, supply contract flexibility and alternate suppliers (Tomlin, 2006). At production and distribution, flexibility entails the ability to quickly change outputs or the mode of delivery, for example, via multi-sourcing, delayed commitment/production, alternate distribution channels and fast re-routing of requirements (Carvalho et al., 2012a, 2012b). "Financial Strength" (IO9) concerns easily accessible liquid assets and so is a pre-requisite for many of the aforementioned flexibility options ( $\mathrm{Pal}$ et al., 2014).

"Human Resource Management" (IO12) and "Knowledge Management" (IO15) concern aspects of how skills are developed, used and retained in an organisation so as to be able to rapidly adapt to changing job roles in a disruption (Zsidisin and Wagner, 2010). Both are important enablers of an organisation being able to switch sourcing inputs, production processes and distribution approaches. "Market Position" (IO16) concerns factors such as brand equity, customer loyalty, market share and product differentiation, which can influence response and recovery options; thus, "Market Position" can be seen as an enabler of flexibility. For example, in a disruption, a strong brand image combined with good customer communication can enable a supplier to promote substitute

Figure 6 Proposed categorisation of resilience elements identified in the literature

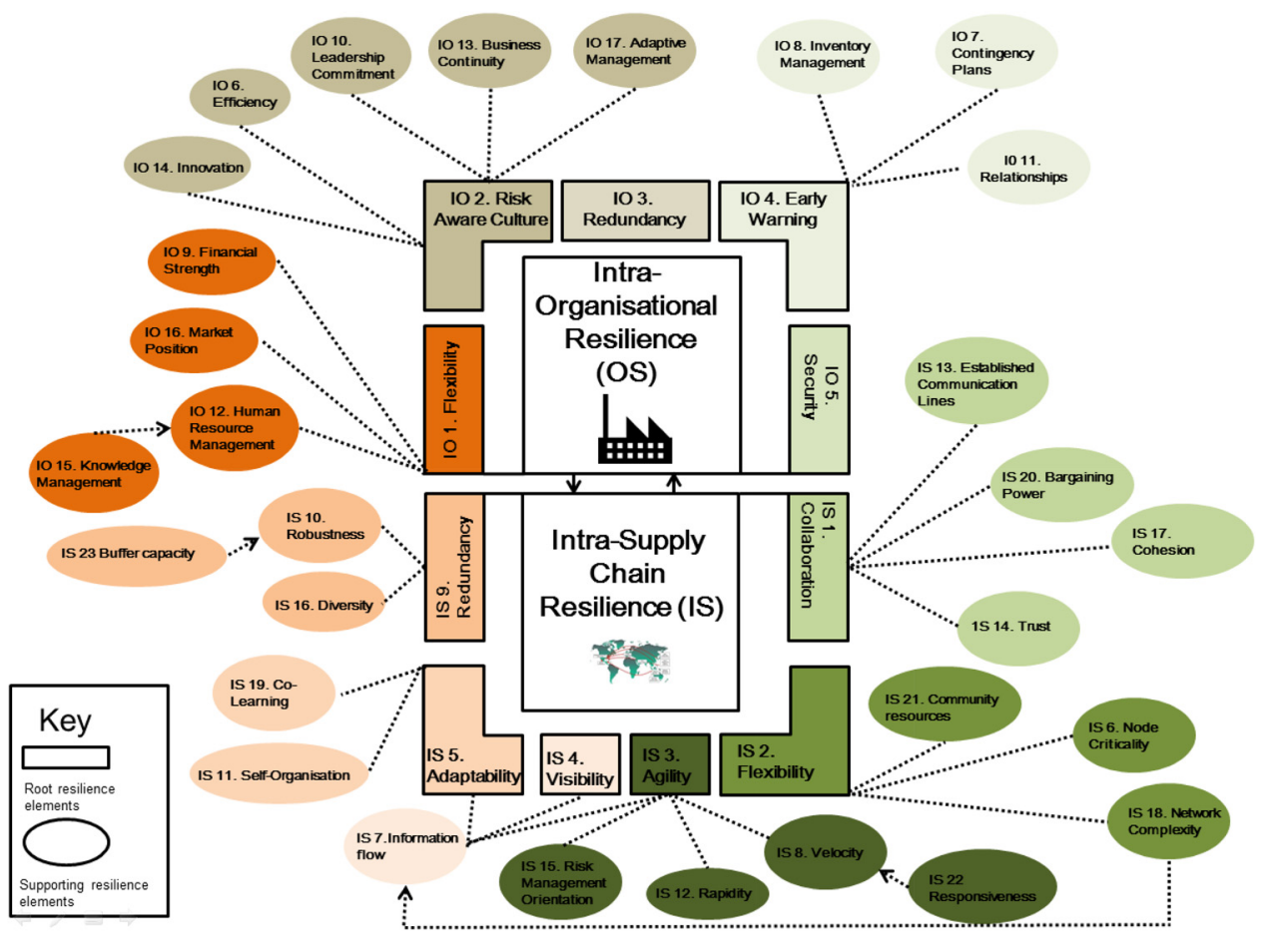


product lines, perhaps even securing future market share (Pettit et al., 2010).

3.3.1.2 Intra-organisational 2: risk aware culture. Risk aware culture was referred to in $\mathbf{1 4 . 7 5}$ per cent of papers reviewed and was used to broadly describe the infrastructure a firm has in place to manage risk. It goes beyond risk management in the sense of an assigned individual(s) simply identifying and mitigating risks on a case by case basis (Finch, 2004; Blome and Schoenherr, 2011; Jüttner and Maklan, 2011; Gölgeci and Ponomarov, 2015). Instead, it concerns the presence of a culture that encourages and enables organisation wide learning and adaptation from past disruptions and also leadership that espouses this (Christopher and Lee, 2004; Peck, 2005). It has been suggested that this may manifest in the form of high organisation wide efficiency, the presence of a business continuity plan and a high degree of joint decision making (Thun and Hoenig, 2011; Neureuther and Kenyon, 2009; Ritchie and Brindley, 2007). These principals were reflected in "Efficiency" (IO6), which concerns how resources are used so as to avoid unnecessary waste and disruption and "Leadership Commitment" (IO10), which concerns the quality of leadership and how it interacts with the rest of an organisation. Equally, "Business Continuity" (IO13), which concerns contingency plans for "mission critical" assets, "Innovation" (IO14), the presence of shared beliefs, openness to learning and joint decision-making both feed into the ability of an organisation to anticipate and respond to risk. Finally, "Adaptive Management" (IO17) which concerns the active monitoring of decisions made in relation to past disruptions and their outcomes enables incremental learning and adaptation to risk. Thus, all are supporting elements of IO2 Risk Aware Culture.

3.3.1.3 Intra-organisational 3: redundancy. Redundancy at the firm level was one of the most commonly cited resilience elements, appearing in 13.1 per cent of papers. Firm level redundancy concerns excess capacity to what is normally required. In this way, it buffers normal activities rather than providing options to do things differently as is the case with the element of "flexibility". One example could be spare inventory capacity, either in terms of ramping up production or in terms of excess storage space or transport capacity (McKinnon, 2006; Aigbogun et al., 2014). However, such approaches typically come at the cost of reduced efficiency and must be matched on an individual basis to specific identified risks (Ponis and Koronis, 2012; Manuj and Mentzer, 2008). It has been suggested that redundancy is best targeted at risk sources from beyond supply chain boundaries (such as natural disasters) and that elements such as "flexibility" are more effective for dealing with intra-supply chain disruptions (Wieland and Wallenburg. 2013).

3.3.1.4 Intra-organisational 4: early warning detection systems. Early warning detection systems were referred to in 8 per cent of papers and concern a broad suite of attributes aimed at providing enhanced foresight of disruption so that an organisation can spend more time preparing and less time reacting to disruption. It includes not only monitoring abilities in the form of physical IT infrastructure but also the staff training and internal information flows that allow effective utilisation of information obtained, particularly with the rise of "Big Data" and The Internet of Things (IOT) (Christopher and Lee, 2004; Stecke and Kumar, 2009). As such, actions which an organisation can put in place internally to maximise warning of disruptions, such as "Inventory Management" (IO8), and to act on them, such as "Contingency Plans" (IO7), and "Relationships" (IO11) are key "Supporting" elements. Clearly, there are major overlaps between early warning detection systems which are considered to be intra-organisation and "visibility" which is often discussed in an interorganisational context.

3.3.1.5 Intra-organisational 5: security. Security concerns defence of assets (including knowledge, staff physical assets) against deliberate attack or intrusion. It is distinct from more general insurance and risk management and is increasingly pertinent in terms of food supply chains, given recent issues with traceability (Pettit et al., 2010; Bakshi and Kleindorfer, 2009; Elleuch et al., 2016a, 2016b).

\subsubsection{Proposed "core" intra-supply chain resilience elements}

3.3.2.1 Intra-supply chain 1: collaboration. Collaboration was cited in 31 per cent of papers reviewed and refers to two or more actors working together to generate advantages that could not be achieved individually (Habermann et al., 2015; Zacharia et al., 2009; Lee, 2014; Scholten and Schilder, 2015). This can range from sharing of limited information to joint decision making, synchronisation of operations and more equal sharing of risk and assets, depending upon end consumer need and the level of trust between partners (Barratt, 2004; Giannakis and Louis, 2011). A number of "Supporting" elements are important in enabling collaboration to occur effectively and these include "Established Communication Lines" (IS13) which can aid the speed and effectiveness of coordination postdisruption as well as "Trust" (IS14) which influences the willingness of entities to talk in the first place. "Cohesion" (IS17), is also closely related as it concerns unifying factors such as mutual end consumers that can drive collaboration. "Bargaining Power" (IS20) concerns factors such as high relative purchasing power that might drive adversarial rather than collaborative supply chain relations. All of these supporting elements are enables of a "collaborative" AFSC.

3.3.2.2 Intra-supply chain 2: flexibility. In a supply chain context, flexibility was cited in 29 per cent of papers. Here, it concerned the degree by which a supply chain can maintain function and respond effectively to changing operating environments and customer requests through partnerships (Lam and Bai, 2016; Richey et al. 2009). It concerns alternate options that partners or the wider operating environment can provide, for example, postponement options, alternate infrastructure, logistics or staff (Gligor and Holcomb, 2012; Stevenson and Spring, 2007). "Node Criticality" (IS6) which concerns relative numbers of single key suppliers or buyers in a supply chain is a key aspect as is "Node Complexity" (IS18) which considers the density of actors in a supply chain and the distances between them (Saenz et al., 2015; Stecke and Kumar, 2009). Interestingly, "Node Complexity" is also a key enabler of "Information Flow" (IS7) in addition to "Flexibility" (IS2), as it determines the efficiency and effectiveness with which information is transmitted within a supply chain (Pereira et al., 2014; Smith et al., 2016). In turn, "Information Flow" (IS7) is a key "Supporting" element of the "Core" elements of "Visibility" (IS4) and "Adaptability" (IS3) highlighting the fact 
that supporting elements can serve to achieve multiple "core" elements. A final supporter of AFSC flexibility is "Community Resources" (IS21) which considers the range of ecological, economic, social, physical, institutional and cultural resources a community can draw upon when faced with disruption (Smith et al., 2016).

3.3.2.3 Intra-supply chain 3: agility. In total, 27.8 per cent of papers referred to agility as a supply chain-wide resilience element. Agility is closely related to flexibility, but whereas flexibility concerns alternative "options", agility relates to how these options are used and particularly the speed at which they can be implemented to recover lost functionality (Sharifi and Zhang, 1999; Dubey et al., 2014). Interestingly, while agility focuses on quick recovery, it does not always have to involve the most efficient response (Braunscheidel and Suresh, 2009; Swafford et al., 2006). As such, "Velocity" (IS8) which concerns the speed and efficiency with which products traverse a supply chain, and "Rapidity" (IS12), which concerns the ability of a supply chain to meet objectives in a timely manner both aid overall agility (Christopher and Lee, 2004; Tendall et al., 2015; Johnson et al., 2013). Additionally, supply chain "Risk Management Orientation" (IS15) which concerns supply chain wide presence of procedures to identify and develop contingency plans for disruptions can enhance recovery speed and effectiveness, thus contributing to agility. Equally, "Responsiveness" (IS22) which concerns a supply chain's ability to respond to consumer demands, particularly via lead time reduction efforts, also supports overall supply chain agility (Saenz et al., 2015; Aramyan et al., 2007).

3.3.2. 4 Intra-supply chain 4: visibility. Visibility is cited by 24 per cent of papers as being a key supply chain scale resilience element. It concerns the ability to see structures, products and processes from one end of the supply chain to the other (Pettit et al., 2013). Clearly therefore, there is major overlap with "Information Flow" (IS7) which concerns effective and efficient flow of information from one end of the supply chain to the other (Soni et al., 2014; Faisal and Banwet, 2006). However, it is not only about information flow but also about directing the right knowledge to the right people at the right time (Christopher and Lee, 2004; Carvalho et al., 2014). Therefore, it is very much about information management. Such information can concern company processes and assets or, alternatively, the wider operating environment, for example, consumer trends and competitor technology. As such, visibility is synergistic with "Collaboration" (IS1) (Brandon-Jones et al., 2014; Gunasekaran et al., 2011; Aigbogun et al., 2014).

3.3.2.5 Intra-supply chain 5: adaptability. Adaptability is a measure of a system's ability to adapt incrementally or to completely transform in response to a changing operating environment (Sinclair et al., 2014; Tukamuhabwa et al., 2015). It is distinct from "Agility" (IS3) which concerns tactical level adaptations and instead focuses on system wide evolution in response to changing operating environments. To be able to do so, a supply chain's "adaptability" is also dependent on the presence of "Self-Organisation" (IS11) which refers to the autonomy, ability and will of a system to internally organise itself as opposed to being driven by external forces. (Milestad and Darnhofer, 2003; Lebel et al., 2006). Equally important is "Co-Learning" (IS19) which involves the procedures in place to aid system wide joint learning from both near misses and actual disruptions (King, 2008; Pettit et al., 2010).

3.3.2.6 Intra-supply chain 9: redundancy. Redundancy at a supply chain scale concerns system-wide design of emergency back-up and storage facilities, surplus pathways between nodes and the extent to which different supply chain nodes and components are replaceable (Bode et al., 2011; Ratick et al., 2008). It was cited by 9 per cent of papers reviewed as being a key supply chain wide resilience enabler. An important "Supporting" element is "Robustness" (IS10) which is a marker of a system's ability to absorb change without losing core functionality (Ivanov et al., 2015). In turn, the principles of "Robustness" seem to be almost identical to those of "Buffer Capacity" (IS23) (Milestad and Darnhofer, 2003; Spiegler et al., 2012). "Diversity" (IS16) has also been linked to redundancy in the context of different skill sets that can be used to reach the same outcome at a supply chain level (Fiksel, 2003).

Having identified relevant resilience elements from the literature, this section now completes $Q 1.2$ by exploring the resilience strategies that help an organisation to identify what resilience elements to use in a given situation and time. It was observed that one of the more common approaches in the literature was to focus on resilience elements with the highest citation factor (Manuj and Mentzer, 2008; Christopher and Lee, 2004; Ratick et al., 2008). In very industry specific works, this approach is effective, however, as was identified in the introduction of this review, AFSCs must consider a broad range of risks stemming from social, environmental and economic drivers. This means that the right resilience element might not always be the most highly cited element. This is addressed in Figure 6 by the proposal of a range of "Core" and more focussed "Supporting" elements that are highly situation specific. However, this means that there is a need for a more thorough implementation strategy.

One solution is to use the "phases" of disruption which were identified in addressing $Q 1.1$ as being major components of many resilience definitions in the literature. These phases are "Readiness" (the ability to anticipate potential disruptions), "Response" (the ability to mitigate the impact of a disruption as it happens) and "Recovery" (the ability to return to core function and repair losses rapidly) as identified by Ponomarov and Holcomb (2009). Added to these three is "Growth" (the ability to adapt for competitive advantage) as described by Hohenstein et al. (2015). Hohenstein et al. (2015) further develop the use of phases by attempting to match a small number of resilience elements to a "Proactive" Strategy (aligned to the "Readiness" phase) and "Reactive" Strategy (aligned to the "Response", "Recovery" and "Growth" Phases). While useful and novel, the proposed groupings consist of a narrow range of the elements compared to those identified by this review (Figure 6), and furthermore, these are heavily orientated towards organisational competitiveness, rather than how a complex system, such as an AFSC, can maintain function and adapt.

The authors of this review therefore propose the categorisation of the resilience elements identified (Figure 6) by phase as presented in Figure 7. For consistency, the "Readiness", "Response" and "Recovery" phases identified by Ponomarov and Holcomb (2009) have been retained. In this 
Figure 7 Proposed strategy for using resilience elements based on phase of disruption

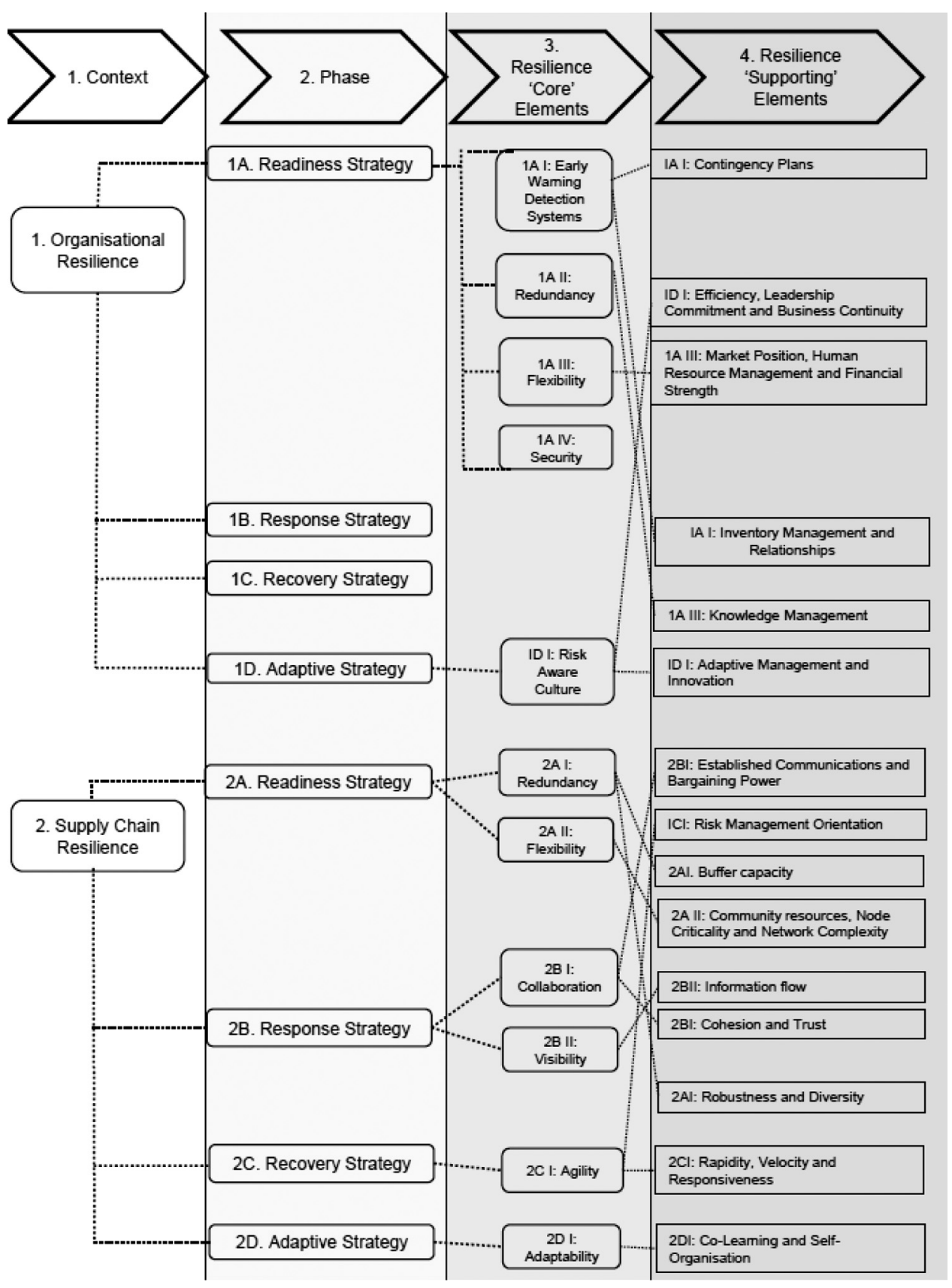

context, elements categorised in the Readiness Phase concern elements that assist in monitoring changes to the operating environment and those which, while being useful in later phases, must be built in in advance. Elements in the Response Phase focus on mitigating the impact of disruption and helping to maintain functionality. Elements in the Recovery Phase are orientated towards minimising the time needed to restore any lost functionality and enabling adaptation at an operational level (such as accepting new ingredients or distribution routes). In this review, the "Growth" phase identified by Hohenstein et al. (2015) has been renamed as the "Adaptive" phase. This is because the context of the growth phases supports the notion of competitive advantage and incremental improvement of the pre-disruption state of equilibrium (Hohenstein et al.,2015).

However, exploration of the adaptive theory of resilience (addressed in Q1.1), suggests that the focus of this phase in an AFSC context should be the alignment of core values with an ever-changing operating environment. Therefore, adaptive phase elements concern the ability for long term, system wide, adaptation, perhaps significantly affecting core function, in response to changing operating environments.

At an organisational level, four of the five "Core" resilience elements are readiness phase elements. Early warning detection by nature involves techniques of generating forewarning of 
possible disruptions ahead. Flexibility, redundancy and security must all be built in advance (Pettit et al., 2010; Manuj and Mentzer, 2008). None are free, and this necessitates careful matching to vulnerabilities identified by early warning detection. Risk aware culture, the final organisational "Core" resilience element, is an adaptive phase element due to its focus on systemic learning from past disruptions, and joint decisionmaking to bolster future preparedness. Interestingly, "Supporting" elements are not necessarily used at the same stage as their matching "Core" element. For example, under the "Core" element of Early Warning Detection Systems, the "Supporting" element "Contingency Planning" is a readiness phase element; however, the "Supporting" elements of "Inventory Planning" and "Relationships" between teams and individuals, while established in preparation, are actually used at the response phase.

At a supply chain level, distribution of "Core" elements by phase is much more even, with redundancy and flexibility appearing as readiness phase elements, collaboration and visibility as response phase elements, agility as a recovery phase element and adaptability as an adaptive phase element. Flexibility and redundancy concern advanced design of products, processes, infrastructure and transport routes in preparation for disruption (Sheffi and Rice, 2005; Stecke and Kumar, 2009). Collaboration and visibility concern relative ability to work with supply chain partners to mitigate disruption and maintain core function. While they are supplemented by readiness phase activities such as contingency planning and establishing IT infrastructure, the actions themselves are commonly cited as response elements (Jüttner and Maklan, 2011; Scholten et al., 2014). Agility is most commonly cited as a recovery element and is concerned with the ability to rapidly make good lost functionality through making tactical changes in response to the new operating environment (Wieland and Wallenburg, 2013; Braunscheidel and Suresh, 2009). Adaptability on the other hand is an adaptive phase element and concerns the relative freedom a supply chain has to fundamentally realign itself at a strategic level post disruption. This might be, for example, a system-wide overhaul of logistics, but to do so, there needs to be a culture of discussion and joint learning/decision-making across supply chain partners (Estrada-Flores et al., 2009).

\subsection{Addressing Q1.3}

This paper has so far analysed the multi-disciplinary definitions, elements and strategies concerning resilience and identified aspects that are of importance to AFSCs. In addressing $Q 1.3$, this paper will now synthesise the identified multidisciplinary aspects of resilience into a conceptual framework of AFSC resilience.

As identified in addressing Q1.1, AFSCs are complex socioecological systems with interactions occurring across different scales, distances and periods, all of which must be assessed together to accurately model resilience. This review has identified a number of unique food system challenges, summarised as follows (Diabat et al., 2012; Higgins et al., 2010; Taylor and Fearne, 2006):

1 A network of potentially thousands of participants, in stark contrast to the widely accepted view of a linear buyer-seller chain reaching from farm to consumer.
- It is important to appreciate that a vast range of supporting dependencies such as equipment suppliers, fuel infrastructure, financial services and logistics, among others, enable food to reach end consumers.

2 Strong social drivers, such as health, lifestyle, the need to protect the natural world, as well as economic goals.

3 Strong genetic, environmental and climatic variability.

- Food products are naturally variable in colour, shape and size even before the effect of the growing environment and particularly climate change are considered in terms of their effect on yield.

4 Low-value end products.

- Food is typically purchased frequently and represents a low proportion of household expenditure in relation to other consumer goods such as electronics (although it is accepted that proportion of household expenditure can vary significantly depending on location).

5 Declining margins.

- A range of factors, in addition to those described in challenge (d), including globalisation and the increasing dominance of large multiple food retailers, are driving ever lower margins in AFSCs.

Figure 8 explores how these challenges manifest as unique risk sources for each of the traditional AFSC stages: primary production, processing, distribution, catering, retail and consumption (Elleuch et al., 2016a, 2016b).

Primary producers face a range of natural stressors which put yield and quality at risk, such as disease and bad weather, as well as anthropogenic damage to natural capital such as pollination, soil fertility and water access. Historically, they have also faced major downstream pressure from buyers which has squeezed their margins, often driving smaller farmers, and thus production diversity, out of business.

Food processors, who historically held much more supply chain power, are similarly facing downwards pressure from large retailers, favouring "lean" approaches which reduce non-value adding activities, thus reducing flexibility and redundancy (Van der Vorst and Beulens, 2002). Increasingly, viability is dependent on brand differentiation, a gap which retailers are fast closing with their own "private labels".

Wholesalers are traditional stock holders in AFSCs and major risks stem from a reduction in customer base as smaller "cash and carry" buyers are being replaced by large supermarkets. Catering is commonly the biggest source of value in modern AFSCs. Key strengths include customer responsiveness and diversity, although there is some risk from market concentration.

Retailers themselves are often described as the gateways of modern AFSCs due to their market share and proximity to end consumers. Yet, the "Just in Time" models which enable them to offer high variety and value leaves them at risk of supply disruption. Their proximity to consumers also means that they can have less time to react to changing consumer demands.

The resilience of each stage described so far is vital in ensuring food security, or in more specifically, that food is physically available (ready for consumption in principle), accessible (somewhere the consumer can access it), acceptable (in a form that is culturally acceptable), safe and reliable. 
Figure 8 Unique AFSC risk sources from a whole supply chain perspective and that of individual actors within a given AFSC

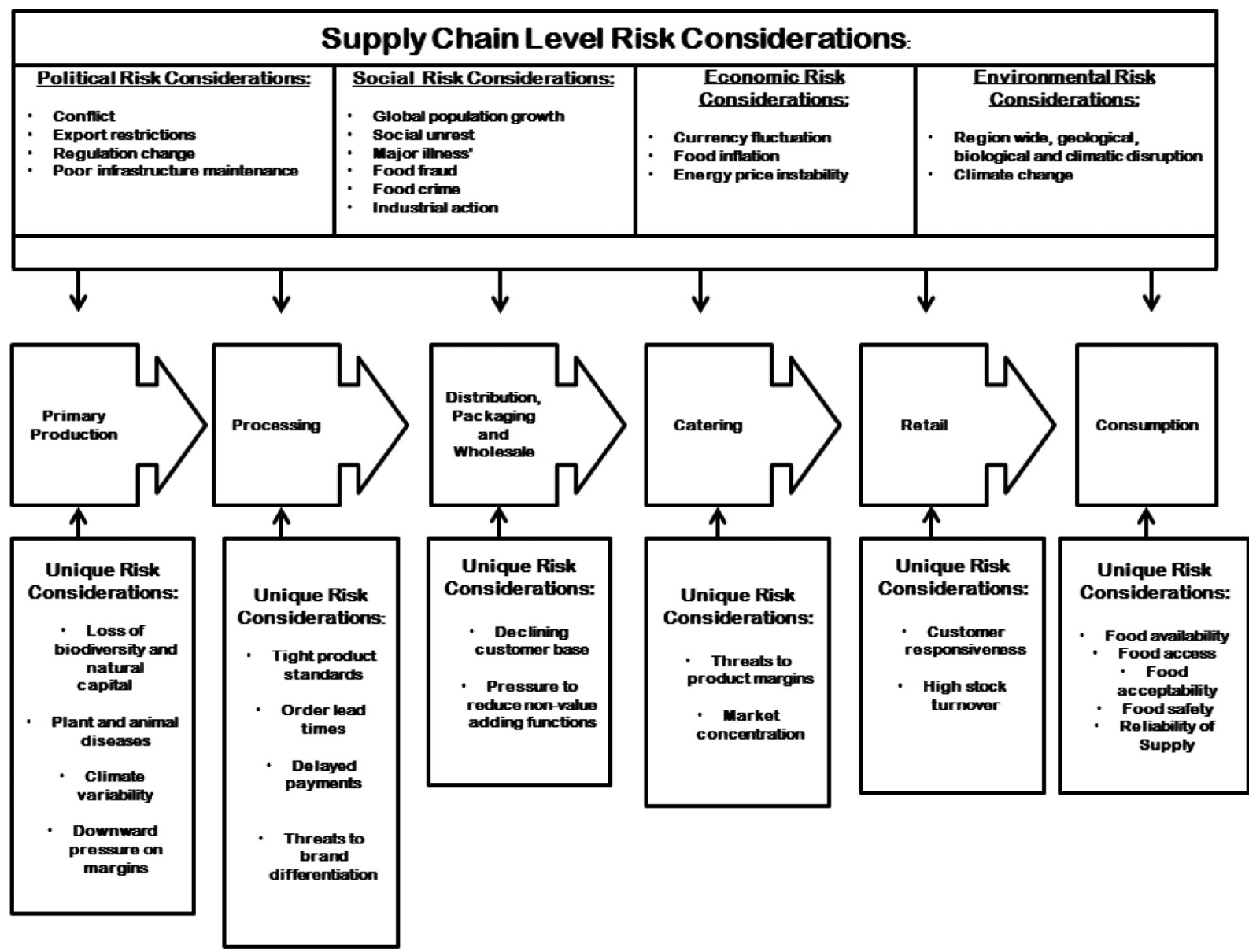

In addition to their own unique risks, all of the stages together are influenced by a number of overarching risk sources in the wider social, political, environmental and economic spheres (Colicchia et al., 2010; Vlajic et al., 2013). These risk sources can often be separated by significant distance and even periods from a given organisation or supply chain and their impacts are not linear (Vlajic et al., 2012). For example, recent extreme weather in key regions of Spain and Italy decreased production by as much as 60 per cent. Due to retailer sourcing policies across the continent, many initiated decades ago, where focus was placed on a relatively small number of large-scale intensive producers, often purely for economic reasons, large sections of Europe suffered severe vegetable shortages in the winter of 2016-2017. Due to the growing times of crops, and length of buyer contracts, such disruptions can take many months to resolve (Food Navigator, 2017). Thus, it is vital that distance, time and scale are considered together.

One approach to addressing this issue is to break down AFSCs into constituent stages and optimise them based on average operating conditions, perhaps by identifying resilience elements and strategies as has been attempted at a farm, processing, retail and community level in the literature (Milestad and Darnhofer, 2003; King, 2008; Leat and
Revoredo-Giha, 2013; Macfadyen et al., 2015). However, optimising individual stages of a supply chain in this way does not necessarily allow them to adapt to novel situations, and it is possible that optimising one stage may be detrimental to upstream or downstream stages which is unacceptable if the end goal is a more reliable food system overall.

In response, the authors of this review propose that the adaptive definition of resilience is an important lens through which any understanding of AFSC resilience must be built. The adaptive definition prioritises the role of cross-scale system component interactions to the point that external volatility is presumed to be a permanent feature and as such, rather than being a one-off fix, resilience must be seen as a cyclical process of "conservation", "release", "reorganization" and "exploitation". In particular, similarities between the drive towards concentration of assets and connectivity in today's global AFSCs and the "conservation" phase suggest vulnerability to major disruptions.

In addressing $Q 1.2$, this paper identified the importance of capturing multidisciplinary "Supporting" elements of resilience, which reflect the role of social and environmental components of AFSCs rather than the traditional economic buyer-seller relations described in many supply chain works. These resilience elements are vital in addressing the unique 
AFSC risk sources identified previously. This review has also identified the importance of phase-based strategies of identifying which "Core" and "Supporting" resilience elements should be used and when. Therefore, the framework of AFSC resilience proposed is a synergistic one, combining the ecological science understanding of adaptive systems and "panarchy", with resilience elements and strategies originating from SCM. A descriptive example of this framework can be found in Figure 9.

The framework proposes that parallels can be drawn between the four stages of the adaptive cycle (conservative, release, reorganisation and exploitation) and the four phases of a disruption, respectively (readiness, response, recovery and adaptation). It is proposed that there is similarity between the readiness phase of a disruption and the conservation stage of the adaptive cycle due to both considering the relative preparedness of a system before a disruption. There are also similarities between the response phase of a disruption and the release stage of the adaptive cycle, as both focus on the effects of a disruption. Similarly, there are overlaps between the recovery phase of a disruption and the reorganisation stage of the adaptive cycle as both concern regaining functionality. Finally, overlaps also exist between the adaptive phase of a disruption and the exploitation stage of the adaptive cycle, as both involve growth potential as a result of adaptation to previous disruptions.
These relations are exemplified in Figure 9 from the perspectives of an organisation, in this case a food processor, and the overarching food supply chain. Each faces a unique example risk from those categorised in Figure 8; the food processor a novel food product launched by a competitor unexpectedly and the supply chain, a serious regional natural disaster.

By dividing the disruption into phases, the food processor and the broader supply chain are able to assign bespoke mitigating resilience "elements" from those categorised in Figure 6. To better reflect characteristics of AFSCs, such as their importance to end consumer food security and diverse range of stakeholders, the actions for each resilience "element" are divided into social, environmental and economic indicators. This distinguishes them from previous works which have applied resilience elements for the purpose of organisational competitiveness. Not only do these three indicators represent the broad dependencies of food systems but they are also commonly used as the three pillars of sustainability; thus, the framework underpins the synergistic relationship between resilience and sustainability identified by others. Using the example of the supply chain, actions at the response phase where collaboration was identified as a suitable "Core" element include the need to work together as a supply chain to ensure food is available, safe and accessible to consumers. At an environmental level, the caveat is added that efforts to get food

Figure 9 Example application of proposed AFSC framework synthesising the adaptive cycle of resilience with resilience elements and phases

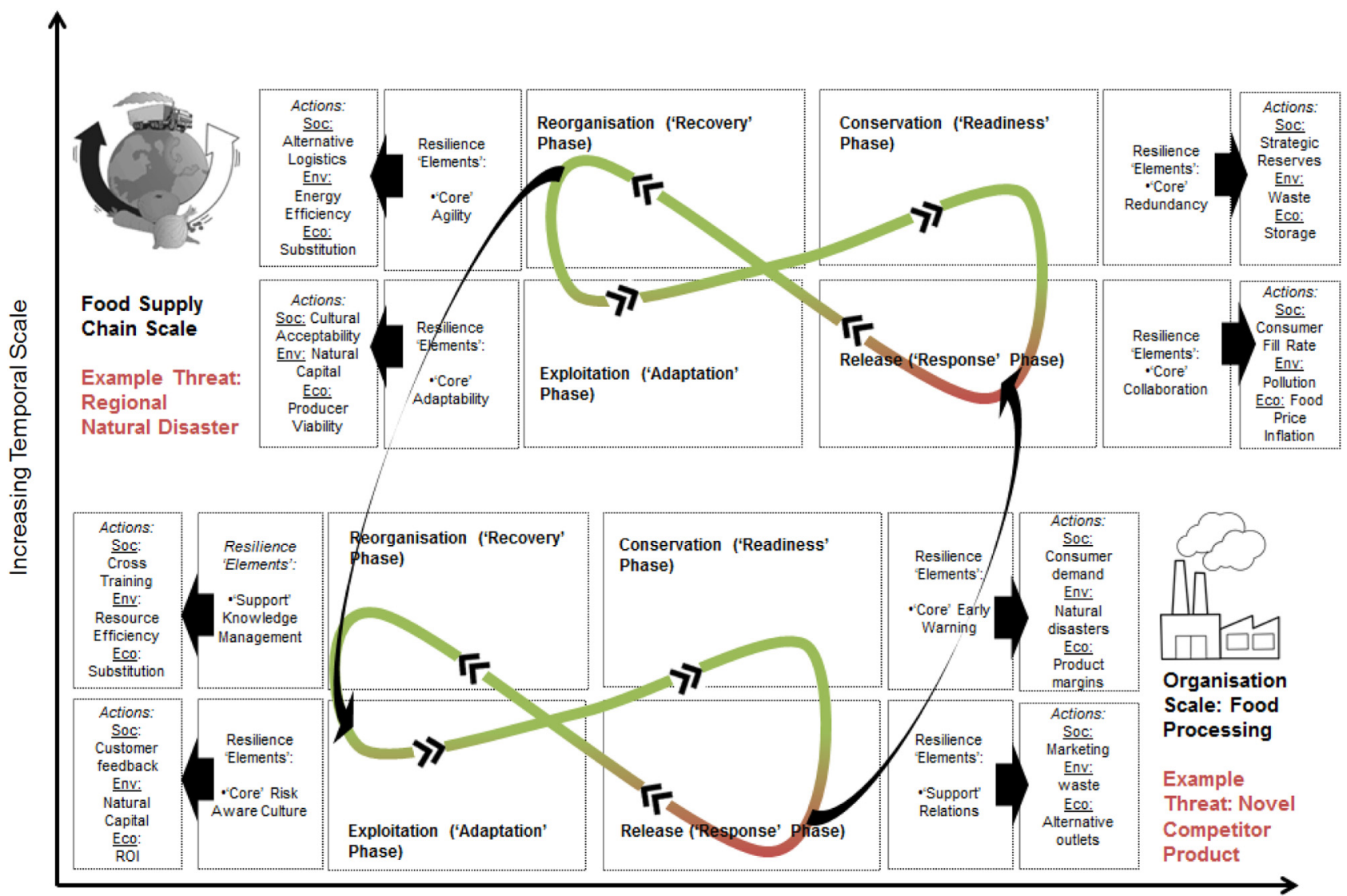

Increasing Spatial Scale 
to consumers, perhaps by using alternative logistics, do not come at the cost of excessive pollution.

Economically, it is vital that organisations do their best not to exploit competitive advantage and drive food price inflation for end consumers. This, of course, is highly idealised, and the reality is that actions by individual organisations, in this example the food processor, to an earlier threat such as product competition, may actually preclude them from working collaboratively at a supply chain level. This represents a major advantage of using the adaptive model because it can explore the cross-scale interactions that can take place over great geographical and temporal distances.

A further key advantage of using the adaptive cycle as a basis for an AFSC framework is that it is cyclical in nature. In other words, there are no optimised "states of equilibrium" for an organisation to work towards, and this makes it inherently better suited to describing volatile operating environments, where disruptions are continuous, such as food systems, as illustrated in Figure 10. As such, the emphasis is on ingraining resilience across all activities, rather than as a one-off tool to address individual disruption risks, and in doing so, resilience becomes cumulative. In this way, a resilient food system is more of a safe-fail system rather than a fail-safe system (Anderies et al., 2013).

\section{Implications for supply chain theory and practice}

In light of a number of recent high-profile disruptions to AFSCs such as the 2007-2008 food price spikes, the winter
2016-2017 European vegetable disruptions and projected future volatility, this review was designed to explore how the increasingly popular topic of resilience can be applied to AFSCs. In meeting this objective, definitions, elements and strategies of resilience were investigated, analysed based on their suitability for AFSCs and synthesised into a novel framework of AFSC resilience which considers AFSCs as complex systems rather than constituent organisational competitiveness, as has been the focus in the past.

This presents a number of implications at a practical level in terms of management and policy. Findings suggest that it is important to consider a wide range of resilience elements which go beyond the most commonly cited "Core" elements and to consider "Supporting" elements. Such "Supporting" elements often consider the broader relationships, knowledge management and capacities for learning and adapting which are vital in achieving "Core" elements such as flexibility and redundancy. These "Supporting" elements are also vital in understanding AFSC resilience from an "adaptive cycle" perspective, as they enable the links between organisational resilience strategies and broader supply chain wide resilience to be better understood. Ignoring such "Supporting elements" and the cross-scale interactions between different geographical and temporal points in a supply chain will restrict a given organisation's resilience to outside volatility (Caschili et al., 2015).

Appreciating such links is important for ensuring that food systems are robust enough to guarantee food availability, access and acceptability which are three of the four main areas of food security, which in turn, is arguably the ultimate goal of food

Figure 10 The cumulative nature of resilience

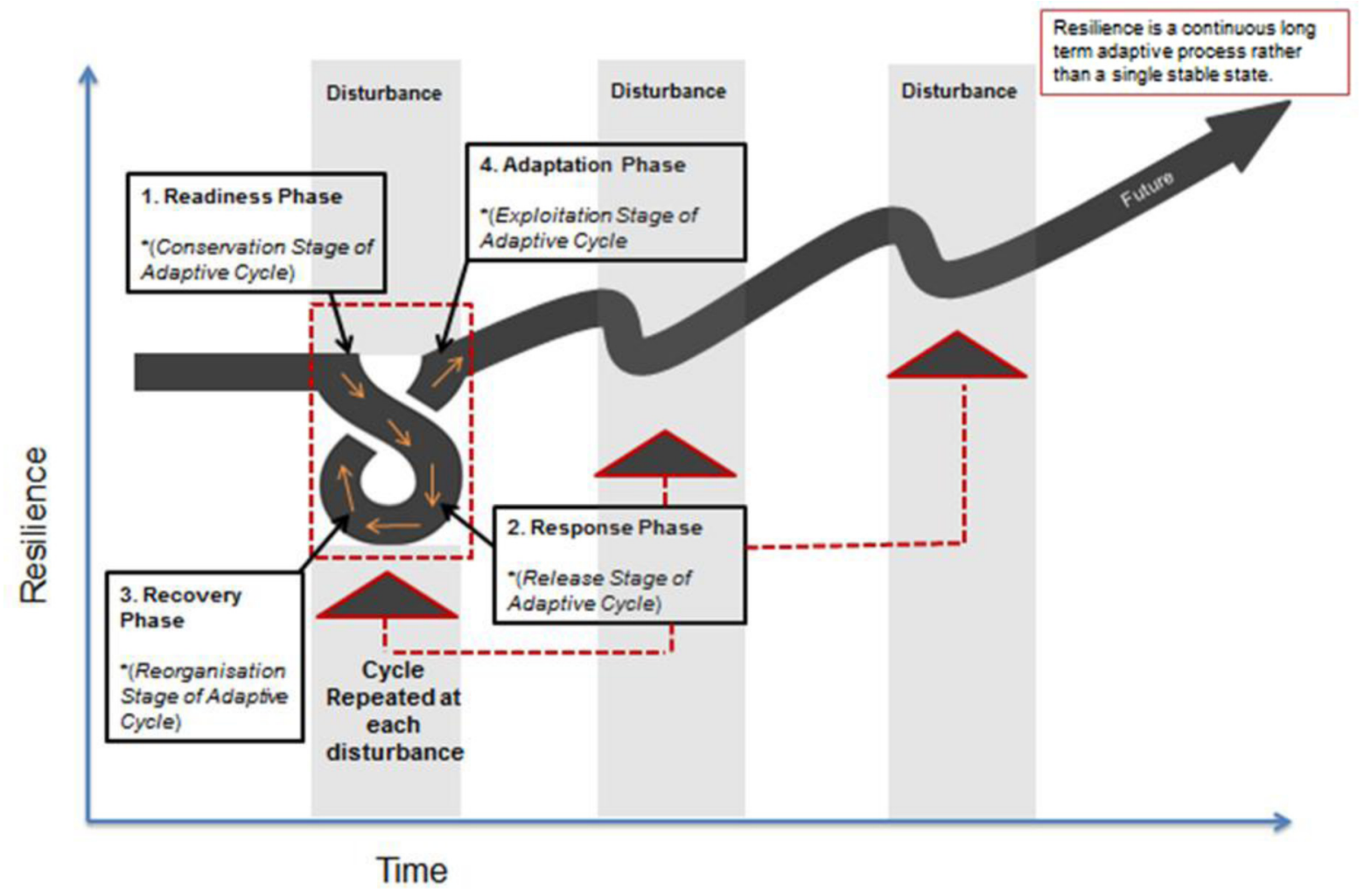


systems. In achieving the fourth goal, reliability, the broader sustainability impacts of chosen resilience elements must be considered, and this is enabled by using social and environmental, in addition to more traditional economic, indicators. Linked to this is the need to design resilience strategies around the different phases of disruption in which a resilience element must be implemented. This is vital because resilience elements often have a cost and, unless carefully matched to a specific vulnerability, can be highly resource inefficient and harmful to long-term sustainability (Tang, 2006).

From a theory perspective, this review has identified what appears to be a growing consensus that the adaptive definition is best suited to describing supply chain and particularly AFSC resilience (Table IV). Furthermore, the focus of works across multiple disciplines appears to have moved on from definitions towards proposing resilience "elements" and "strategies". However, to be useful in an adaptive context, it is imperative that such resilience "elements" and "strategies" consider not only an immediate organisation, or even its supply chain partners, but also broader social and environmental supply chain dependencies and their cross-scale interactions. In response to this challenge, this review comprehensively categorises 40 resilience elements from multiple research fields into "Core" and "Supporting" elements, enabling the valuation of less commonly cited elements which enable the ability to adapt and consider different spatial and temporal scales.

Yet, the framework proposed is conceptual in nature, and to help advance AFSC resilience theory, there is a need for empirical validation of the elements that help actors at the different stages of an AFSC (Figure 8) to be resilient. There is also need for further development of the social, economic and environmental indicators proposed in Figure 9 which help organisations to "action" a given element whilst underpinning their resilience strategy in good sustainability practice. This is part of a broader need for future works to develop strategies for implementing resilience "elements" that aid wider supply chain delivery of food security, rather than strengthening individual organisations within that supply chain.

\section{Conclusions}

Resilience of national and global food systems is an increasingly important topic in light of growing volatility induced by challenges as diverse as climate change, population growth and resource constraints. Despite a growing interest in the concept of resilience from a number of research fields, a number of factors including the focus on food security as a priority, rather than economic competitiveness, as well as unique attributes of food as a biological resource, mean that these works are not readily adoptable by AFSCs. In response, this review systematically reviewed 137 relevant works to address $Q 1$. To support this objective, the findings were analysed in the form of three review sub-questions.

In answering $Q 1.1,48$ papers offered definitions, all of which were based on one of either the engineering definition (single optimum state of equilibrium), the ecological definition (multiple possible states of equilibrium) or the adaptive definition (no states of equilibrium, but rather a constant process of evolutionary learning in response to constant changes stemming from external systems). Analysis of publication dates suggest that the adaptive definition is increasingly accepted as the most appropriate way of describing complex systems such as supply chains, particularly AFSCs. A number of definitions referred to the abilities of readiness, response and recovery as being key resilience enablers and adaptive definitions often added a fourth capacity which was to "adapt" after disruptions, thus ensuring that resilience is relative to operating environments and not static idealised conditions. Yet, in many works, the priority of resilience is often organisational competitiveness. The findings suggest that for AFSCs the goal should be food security and therefore the following definition of AFSC resilience is proposed: The collective ability of AFSC stakeholders to ensure acceptable, sufficient and stable food supplies, at the required times and locations, via accurate anticipation of disruptions and the use of strategies which delay impact, aid rapid recovery and allow cumulative learning post-disruption.

In answering the first part of Q1.2, 40 unique resilience elements were identified from 61 papers. A small number of elements received the majority of citations, and this was often how resilience "strategies" were formed in the literature (Hohenstein et al.,2015). Many of the less commonly cited elements explore interactions and relations between organisations, communities and the natural environment, as well as their ability to adapt, and this has important implications for how individual company actions can interact across spatial and temporal scales with broader AFSC resilience. In response, the unique categorisation of resilience elements into "Core" and "Supporting" elements is proposed to capture this value. sThis approach also allows the alignment of each to a relevant "phase" of disruption (readiness, response, recovery and adaptation) and in doing so, forms a more comprehensive resilience implementation "strategy".

In addressing Q1.3, relevant findings concerning resilience definitions, elements and strategies from the previous two review sub-questions were synthesised to propose a hybrid adaptive cycle-resilience element framework that was underpinned by a number of stage specific risks and characteristics of AFSCs. In this framework, it is proposed that resilience elements and their phases of use can be associated with the key principles of the adaptive cycle, namely, conservation, release, recovery and exploitation. In linking the two, the cyclical nature of disruptions is highlighted, reinforcing the cumulative nature of resilience efforts. Furthermore, because the adaptive cycle is designed with systems in mind, it captures the links between resilience elements used at an organisational level and their impacts on the corresponding adaptive phase in the wider supply chain. Not only is such a hybrid approach unique in its own right, but the application of AFSC stage-specific risk sources and indicators that consider social and environmental impacts, as well as the more traditional economic performance measures, when considering which resilience elements to use, better align this framework with food security and long-term sustainability rather than economic competitiveness. 


\section{Limitations and future work}

This review has provided a timely and rigorous systematic review of a range of multidisciplinary works relevant to resilience in an AFSC context. Its novelty lies primarily in the synthesis of relevant concepts from a range of disciplines to form a more holistic view of AFSC resilience than would have been possible from reading any piece of the review material in isolation. However, it is at base a conceptual piece of work, which is restricted to information published in the peer reviewed literature. As such, while the authors feel that the practical implications of this work are potentially significant due to their ability to help align resilience at an organisational level with wider societal food security, empirical validation of the resilience elements and strategies described is a key next step. Furthermore, the framework described in Figure 9 is orientated towards developed world supply chain structures and specific risks in this context. However, resilience is equally pressing in developing world supply chains, particularly given the greater prevalence of subsistence agriculture in such regions and the fact that it is in the developing world that a great proportion of global population growth and urbanisation is projected to occur (United Nations, Department of Economic and Social Affairs, Population Division, 2015; Gorton et al., 2014). Here, it is likely that risks will stem from primary production challenges and post-harvest storage issues. This may therefore challenge the suitability of the mitigating resilience elements proposed in this paper. As such, adapting the framework for a developing world setting is something the authors aim to investigate in future work.

\section{References}

Aigbogun, O., Ghazali, Z. and Razali, R. (2014), “A framework to enhance supply chain resilience the case of Malaysian pharmaceutical industry", Global Business and Management Research, Vol. 6 No. 3, p. 219.

Allen, C.R., Angeler, D.G., Garmestani, A.S., Gunderson, L. H. and Holling, C.S. (2014), "Panarchy: theory and application", Ecosystems, Vol. 17 No. 4, pp. 578-589.

Allison, E.H., Perry, A.L., Badjeck, M.C., Neil Adger, W., Brown, K., Conway, D., Halls, A.S., Pilling, G.M., Reynolds, J.D., Andrew, N.L. and Dulvey, N.K. (2009), "Vulnerability of national economies to the impacts of climate change on fisheries", Fish and Fisheries, Vol. 10 No. 2, pp. 173-196.

Ambulkar, S., Blackhurst, J. and Grawe, S. (2015), "Firm's resilience to supply chain disruptions: scale development and empirical examination", fournal of Operations Management, Vols 33/34, pp. 111-122.

Anderies, J., Folke, C., Walker, B. and Ostrom, E. (2013), "Aligning key concepts for global change policy: Robustness, resilience, and sustainability”, Ecology and Society, Vol. 18 No. 2.

Annarelli, A. and Nonino, F. (2016), "Strategic and operational management of organizational resilience: current state of research and future directions", Omega, Vol. 62, pp. 1-18.

Aramyan, L.H., Lansink, A.G., Van Der Vorst, J.G. and Kooten, O. (2007), "Performance measurement in Agrifood supply chains: a case study", Supply Chain Management: An International fournal, Vol. 12 No. 4, pp. 304-315.
Asbjornslett, B.E. (1999), "Assess the vulnerability of your production system", Production Planning \& Control, Vol. 10 No. 3, pp. 219-229.

Bakshi, N. and Kleindorfer, P. (2009), "Co-opetition and investment for supply chain resilience", Production and Operations Management, Vol. 18 No. 6, pp. 583-603.

Barratt, M. (2004), "Understanding the meaning of collaboration in the supply chain", Supply Chain Management: An International foumal, Vol. 9 No. 1, pp. 30-42.

Barroso, A.P., Machado, V.H. and Machado, V.C. (2011), Supply Chain Resilience Using The Mapping Approach, InTech, p. 161.

Barthel, S. and Isendahl, C. (2013), "Urban gardens, agriculture, and water management: sources of resilience for long-term food security in cities", Ecological Economics, 28 February, Vol. 86, pp. 224-234.

Benton, T., Gallani, B., Jones, C., Lewis, K. and Tiffin, R. (2012), "Severe weather and UK food chain resilience", Detailed Appendix to Synthesis Report (Biotechnology and Biological Sciences Research Council, available at: www.foodsecurity.ac.uk/assets/ pdfs/frp-severe-weather-uk-food-chain-resilience.pdf

Berle, O., Asbjørnslett, B.E. and Rice, J.B. (2011), "Formal vulnerability assessment of a Maritime transportation system”, Reliability Engineering \& System Safety, Vol. 96 No. 6, pp. 696-705.

Blome, C. and Schoenherr, T. (2011), "Supply chain risk management in financial crises-a multiple case-study approach", International journal of production economics, Vol. 134 No. 1, pp. 43-57.

Bode, C., Wagner, S.M., Petersen, K.J. and Ellram, L.M. (2011), "Understanding responses to supply chain disruptions: insights from information processing and resource dependence perspectives", Academy of Management fournal, Vol. 54 No. 4, pp. 833-856.

Brandon-Jones, E., Squire, B., Autry, C.W. and Petersen, K.J. (2014), "A contingent resource based perspective of supply chain resilience and robustness", fournal of Supply Chain Management, Vol. 50 No. 3, pp. 55-73.

Braunscheidel, M.J. and Suresh, N.C. (2009), "The organizational antecedents of a firm's supply chain agility for risk mitigation and response", fournal of Operations Management, Vol. 27 No. 2, pp. 119-140.

Bruneau, M., Chang, S.E., Eguchi, R.T., Lee, G.C., O’Rourke, T.D., Reinhorn, A.M., Shinozuka, M., Tierney, K., Wallace, W.A. and Von Winterfeldt, D. (2003), "A framework to quantitatively assess and enhance the seismic resilience of communities", Earthquake Spectra, Vol. 19 No. 4, pp. 733-752.

Carvalho, H., Azevedo, S.G. and Cruz-Machado, V. (2014), "Supply chain management resilience: a theory building approach", International fournal of Supply Chain and Operations Resilience, Vol. 1 No. 1, pp. 3-27.

Carvalho, H., Cruz-Machado, V.H. and Tavares, J.G. (2012a), "A mapping framework for assessing supply chain resilience", International fournal of Logistics Systems and Management, Vol. 12 No. 3, pp. 354-373.

Carvalho, H., Barroso, A.P., Azevedo, S. and Cruz-Machado, V.H. (2012b), "Supply chain redesign for resilience using simulation", Computers \& Industrial Engineering, Vol. 62 No. 1, pp. 329-341. 
Caschili, S., Medda, F.R. and Wilson, A. (2015), “An interdependent multi-layer model: resilience of international networks", Networks and Spatial Economics, Vol. 15 No. 2, pp. 1-23.

Christopher, M. and Holweg, M. (2011), "Supply chain 2.0: managing supply chains in the era of turbulence", International Fournal of Physical Distribution \& Logistics Management, Vol. 41 No. 1, pp. 63-82.

Christopher, M. and Lee, H. (2004), "Mitigating supply chain risk through improved confidence", International fournal of Physical Distribution E Logistics Management, Vol. 34 No. 5, pp. 399-396.

Christopher, M. and Peck, H. (2004), "Building the resilient supply chain", The International Fournal of Logistics Management, Vol. 15 No. 2, pp. 1-14.

Cimellaro, G.P., Reinhorn, A.M. and Bruneau, M. (2010), "Framework for analytical quantification of disaster resilience", Engineering Structures, Vol. 32 No. 11, pp. 3639-3649.

Colicchia, C. and Strozzi, F. (2012), "Supply chain risk management: a new methodology for a systematic literature review", Supply Chain Management: An International fournal, Vol. 17 No. 4, pp. 403-418.

Colicchia, C., Dallari, F. and Melacini, M. (2010), "Increasing supply chain resilience in a global sourcing context", Production Planning \& Control, Vol. 21 No. 7, pp. 680-694.

Cox, A. and Chicksand, D. (2005), "The limits of lean management thinking: multiple retailers and food and farming supply chains", European Management fournal, Vol. 23 No. 6, pp. 648-662.

Dani, S. and Deep, A. (2010), "Fragile food supply chains: reacting to risks", International fournal of Logistics Research and Applications, Vol. 13 No. 5, pp. 395-410.

Datta, P.P., Christopher, M. and Allen, P. (2007), “Agentbased modelling of complex production/distribution systems to improve resilience", International fournal of Logistics Research and Applications, Vol. 10 No. 3, pp. 187-203.

Davoudi, S., Shaw, K., Haider, L.J., Quinlan, A.E., Peterson, G.D., Wilkinson, C., Fünfgeld, H., McEvoy, D., Porter, L. and Davoudi, S. (2012), "Resilience: a bridging concept or a dead end?" Reframing resilience: challenges for planning theory and practice interacting traps: Resilience assessment of a pasture management system in Northern Afghanistan urban resilience: what does it mean in planning practice? Resilience as a useful concept for climate change adaptation? The politics of resilience for planning: A cautionary note", Planning theory E practice, Vol. 13 No. 2, pp. 299-333.

Denyer, D. and Tranfield, D. (2009), "Producing a systematic review".

Derissen, S., Quaas, M.F. and Baumgärtner, S. (2011), "The relationship between resilience and sustainability of ecological-economic systems", Ecological Economics, Vol. 70 No. 6, pp. 1121-1128.

Diabat, A., Govindan, K. and Panicker, V.V. (2012), "Supply chain risk management and its mitigation in a food industry", International Fournal of Production Research, Vol. 50 No. 11, pp. 3039-3050.

Dubey, R., Ali, S. and Aital, P. (2014), "Mechanics of humanitarian supply chain agility and resilience and its empirical validation", International fournal of Services and Operations Management, Vol. 17 No. 4, pp. 367-384.
Durach, C.F., Wieland, A. and Machuca, J.A. (2015), "Antecedents and dimensions of supply chain robustness: a systematic literature review", International fournal of Physical Distribution \& Logistics Management, 2 March, Vol. 45 Nos 1/2, pp. 118-137.

Elleuch, H., Dafaoui, E., Elmhamedi, A. and Chabchoub, H. (2016a), "Resilience and vulnerability in supply chain: literature review", IFAC-PapersOnLine, Vol. 49 No. 12, pp. 1448-1453.

Elleuch, H., Dafaoui, E., Elmhamedi, A. and Chabchoub, H. (2016b), "A quality function deployment approach for production resilience improvement in supply chain: case of agrifood industry", IFAC-PapersOnLine, Vol. 49 No. 31, pp. 125-130.

ESRC Public Policy Seminar (2012), Global Food Security Programme. Economic and Social Research Council (2012). Global Food Systems and UK Food Imports: Resilience, Safety and Security.

Estrada-Flores, S., Higgin, A.J. and Larsen, K. (2009), "Food distribution systems in a climate challenged future: fruit and vegetables as a case study", Proceedings of the Food, Farming E Health Conference, Melbourne, pp. 77-88.

Fahimnia, B. and Jabbarzadeh, A. (2016), "Marrying supply chain sustainability and resilience: a match made in heaven", Transportation Research Part E: Logistics and Transportation Research Part E, Vol. 91, pp. 306-324.

Faisal, M. and Banwet, D.K. (2006), "Supply chain risk mitigation: modeling the enablers", Business Process Management fournal, Vol. 12 No. 4, pp. 535-552.

Falkowski, J. (2017), "Resilience of farmer-processor relationships to adverse shocks: the case of dairy sector in Poland", British Food Fournal, Vol. 117 No. 10, pp. 2465-2483.

Fao, (2012), The State of Food Insecurity in the World, IFAD, pp. 8-11.

Fiksel, J. (2003), "Designing resilient, sustainable systems", Environmental Science \& Technology, Vol. 37 No. 23, pp. 5330-5339.

Finch, P. (2004), "Supply chain risk management", Supply Chain Management: An International fournal, Vol. 9 No. 2, pp. 183-196.

Folke, C. (2006), "Resilience: the emergence of a perspective for social-ecological systems analyses”, Global Environmental Change, Vol. 16 No. 3, pp. 253-267.

Food Navigator (2017), "EU Vegetable Shortage: Crisis or Opportunity?", www.foodnavigator.com/Market-Trends/ EU-vegetable-shortage-Crisis-or-opportunity (accessed 30 May).

Fraser, E.D., Mabee, W. and Figge, F. (2005), “A framework for assessing the vulnerability of food systems to future shocks", Futures, Vol. 37 No. 6, pp. 465-479.

Ghadge, A., Dani, S. and Kalawsky, R. (2012), "Supply chain risk management: present and future scope", The International fournal of Logistics Management, Vol. 23 No. 3, pp. 313-339.

Giannakis, M. and Louis, M. (2011), "A multi-agent based framework for supply chain risk management", fournal of Purchasing and Supply Management, Vol. 17 No. 1, pp. 23-31.

Gligor, D.M. and Holcomb, M.C. (2012), "Understanding the role of logistics capabilities in achieving supply chain agility: a 
systematic literature review", Supply Chain Management: An International fournal, Vol. 17 No. 4, pp. 438-453.

Godfray, H.C., Beddington, J.R., Crute, I.R., Haddad, L., Lawrence, D., Muir, J.F., Pretty, J., Robinson, S., Thomas, S.M. and Toulmin, C. (2010), "Food security: the challenge of feeding 9 billion people", Science (New York, N.Y.), Vol. 327 No. 5967, pp. 812-818.

Gölgeci, I. and Ponomarov, S.Y. (2015), "How does firm innovativeness enable supply chain resilience? The moderating role of supply uncertainty and interdependence", Technology Analysis E Strategic Management, Vol. 27 No. 3, pp. 267-282.

Gorton, M., Salvioni, C. and Hubbard, C. (2014), "Semisubsistence farms and alternative food supply chains", EuroChoices, Vol. 13 No. 1, pp. 15-19.

Gunasekaran, A., Rai, B.K. and Griffin, M. (2011), "Resilience and competitiveness of small and medium size enterprises: an empirical research", International fournal of Production Research, Vol. 49 No. 18, pp. 5489-5509.

Gunderson, L.H. (2001), Panarchy: Understanding Transformations in Human and Natural Systems, Island press.

Habermann, M., Blackhurst, J. and Metcalf, A.Y. (2015), "Keep your friends close? Supply chain design and disruption risk", Decision Sciences, Vol. 46 No. 3, pp. 491-526.

Higgins, A.J., Miller, C.J., Archer, A.A., Ton, T., Fletcher, C. S. and McAllister, R.R. (2010), "Challenges of operations research practice in agricultural value chains", fournal of the Operational Research Society, Vol. 61 No. 6, pp. 964-973.

Ho, W. (2015), "Green manufacturing supply chain design and operations decision support".

Hoek, R., Harrison, A. and Christopher, M. (2001), "Measuring agile capabilities in the supply chain", International Fournal of Operations E Production Management, Vol. 21 Nos 1/2, pp. 126-148.

Hohenstein, N.O., Feisel, E., Hartmann, E. and Giunipero, L. (2015), "Research on the phenomenon of supply chain resilience: a systematic review and paths for further investigation", International fournal of Physical Distribution $\mathcal{E}$ Logistics Management, Vol. 45 No. 1, pp. 90-117.

Holling, C.S. (1973), "Resilience and stability of ecological systems", Annual Review of Ecology and Systematics, Vol. 4 No. 1, pp. 1-23.

Holling, C.S. (1996), "Engineering resilience versus ecological resilience”, Engineering within Ecological Constraints, Vol. 31, pp. 31-44.

Ingram, J.S., Wright, H.L., Foster, L., Aldred, T., Barling, D., Benton, T.G., Berryman, P.M., Bestwick, C.S., BowsLarkin, A., Brocklehurst, T.F. and Buttriss, J. (2013), "Priority research questions for the Uk food system", Food Security, Vol. 5 No. 5, pp. 617-636.

Ivanov, D., Sokolov, B., Solovyeva, I., Dolgui, A. and Jie, F. (2015), "Ripple effect in the time-critical food supply chains and recovery policies", IFAC-PapersOnLine, Vol. 48 No. 3, pp. 1682-1687.

Johnson, N., Elliott, D. and Drake, P. (2013), "Exploring the role of social capital in facilitating supply chain resilience", Supply Chain Management: An International fournal, Vol. 18 No. 3, pp. 324-336.

Jüttner, U. (2005), "Supply chain risk management: Understanding the business requirements from a practitioner perspective", The International fournal of Logistics Management, Vol. 16 No. 1, pp120-141.

Jüttner, U. and Maklan, S. (2011), "Supply chain resilience in the global financial crisis: an empirical study", Supply Chain Management: An International fournal, Vol. 16 No. 4, pp. 246-259.

Jüttner, U., Peck, H. and Christopher, M. (2003), "Supply chain risk management: outlining an agenda for future research", International fournal of Logistics: Research and Applications, Vol. 6 No. 4, pp. 197-210.

Kamalahmadi, M. and Parast, M.M. (2016), "A review of the literature on the principles of enterprise and supply chain resilience: major findings and directions for future research", International Fournal of Production Economics, Vol. 171, pp. 116-133.

Karl, T.R. (2009), Global Climate Change Impacts in the United States, United States Global Change Research Program, Cambridge University Press, New York, NY.

Kastner, T., Rivas, M.J., Koch, W. and Nonhebel, S. (2012), "Global changes in diets and the consequences for land requirements for food", Proceedings of the National Academy of Sciences, Vol. 109 No. 18, pp. 6868-6672.

Kim, Y., Chen, Y.S. and Linderman, K. (2015), "Supply network disruption and resilience: a network structural perspective", Fournal of Operations Management, Vol. 33-34, pp. 43-59.

King, C.A. (2008), "Community resilience and contemporary Agri-ecological systems: reconnecting people and food, and people with people", Systems Research and Behavioral Science, Vol. 25 No. 1, pp. 111.

Kinsey, J., Kaynts, K., Ghosh, K. and Agiwal, S. (2007), Defending the Food Supply Chain: Retail Food, Foodservice and Their Wholesale Suppliers, Food Industry Center, Department of Applied Economics, University of Minnesota.

Kirwan, J., Maye, D. (2013), "Food security framings within the UK and the integration of local food systems", fournal of Rural Studies, Vol. 29, pp. 91-100.

Kleindorfer, P.R. and Saad, G.H. (2005), "Managing disruption risks in supply chains", Production and Operations Management, Vol. 14 No. 1, pp. 53-68.

Lam, J.S.L. and Bai, X. (2016), "A quality function deployment approach to improve Maritime supply chain resilience", Transportation Research Part E: Logistics and Transportation Review, Vol. 92, pp. 16-27.

Leat, P. and Revoredo-Giha, C. (2013), "Risk and resilience in Agri-food supply chains: the case of the ASDA PorkLink supply chain in Scotland", Supply Chain Management: An International fournal, Vol. 18 No. 2, pp. 219-231.

Lebel, L., Anderies, J., Campbell, B., Folke, C., HatfieldDodds, S., Hughes, T. and Wilson, J. (2006), "Governance and the capacity to manage resilience in regional socialecological systems", Ecology and Society, Vol. 11 No. 1.

Lee, C.W. (2014), "Establishing a decision-making model of global supply chain risk management from the perspective of risk and vulnerability", International fournal of Supply Chain and Operations Resilience, Vol. 1 No. 1, pp. 28-53.

Light, R.J. and Pillemer, D.B. (1986), Summing Up: The Science of Reviewing Research, Cambridge, Harvard University Press, Educational Researcher, pp. Xiii +191. 
Lodree, E.J. and Taskin, S. (2008), “An insurance risk management framework for disaster relief and supply chain disruption inventory planning, fournal of the Operational Research Society, Vol. 59 No. 5, pp. 674-684.

Luthar, S.S., Cicchetti, D. and Becker, B. (2000), "The construct of resilience: a critical evaluation and guidelines for future work", Child Development, Vol. 71 No. 3, pp. 543-562.

McDaniels, T., Chang, S., Cole, D., Mikawoz, J. and Longstaff, H. (2008), "Fostering resilience to extreme events within infrastructure systems: characterizing decision contexts for mitigation and adaptation", Global Environmental Change, Vol. 18 No. 2, pp. 310-318.

McKinnon, A. (2006), "Life without trucks: the impact of a temporary disruption of road freight transport on a national economy", Fournal of Business Logistics, Vol. 27 No. 2, pp. 227-250.

McMichael, A.J., Powles, J.W., Butler, C.D. and Uauy, R. (2007), "Food, livestock production, energy, climate change, and health", Lancet (London, England), Vol. 370 No. 9594, pp. 1253-1263.

Macfadyen, S., Tylianakis, J.M., Letourneau, D.K., Benton, T.G., Tittonell, P., Perring, M.P., Gómez-Creutzberg, C., Báldi, A., Holland, J.M., Broadhurst, L. and Okabe, K. (2015), "The role of food retailers in improving resilience in global food supply", Global Food Security, Vol. 7, pp. 1-8.

Manning, L. and Soon, J.M. (2016), "Building strategic resilience in the food supply chain", British Food fournal, Vol. 118 No. 6, pp. 1477-1493.

Manuj, I. and Mentzer, J.T. (2008), "Global supply chain risk management", fournal of Business Logistics, Vol. 29 No. 1, pp. 133-155.

Manyena, S.B. (2006), "The concept of resilience revisited", Disasters, Vol. 30 No. 4, pp. 434-450.

Milestad, R. and Darnhofer, I. (2003), "Building farm resilience: the prospects and challenges of organic farming", Fournal of Sustainable Agriculture, Vol. 22 No. 3, pp. 81-97.

Milman, A. and Short, A. (2008), "Incorporating resilience into sustainability indicators: an example for the urban water sector", Global Environmental Change, Vol. 18 No. 4, pp. 758-767.

Munoz, A. and Dunbar, M. (2015), "On the quantification of operational supply chain resilience", International fournal of Production Research, Vol. 53 No. 22, pp. 6736-6751.

Morgan, A. (2016), Feeding London 2030: Facing the Logistical Challenge, Global 78, UK Warehouse Association, pp. 7-15.

Natarajarathinam, M., Capar, I. and Narayanan, A. (2009), "Managing supply chains in times of crisis: a review of literature and insights", International fournal of Physical Distribution $\mathcal{E}$ Logistics Management, Vol. 39 No. 7, pp. 535-573.

Neiger, D., Rotaru, K. and Churilov, L. (2009), "Supply chain risk identification with value-focused process engineering", fournal of operations management, Vol. 27 No. 2, pp. 154-168.

Neureuther, B.D. and Kenyon, G. (2009), "Mitigating supply chain vulnerability", Fournal of Marketing Channels, Vol. 16 No. 3, pp. 245-263.

Norrman, A. and Jansson, U. (2004), "Ericsson's proactive supply chain risk management approach after a serious Subsupplier accident", International journal of physical distribution El logistics Management, Vol. 34 No. 5, pp. 434-456.
Pal, R., Torstensson, H. and Mattila, H. (2014), “Antecedents of organizational resilience in economic crises - an empirical study of Swedish textile and clothing SMEs", International Fournal of Production Economics, Vol. 147, pp. 410-428.

Paloviita, A., Kortetmäki, T., Puupponen, A. and Silvasti, T. (2016), "Vulnerability matrix of the food system: operationalizing vulnerability and addressing food security", Fournal of Cleaner Production, Vol. 135, pp. 1242-1255.

Peck, H. (2005), "Drivers of supply chain vulnerability: an integrated framework", International fournal of Physical Distribution \& Logistics Management, Vol. 35 No. 4, pp. 210-232.

Pereira, C., Christopher, M. and Lago Da Silva, A. (2014), "Achieving supply chain resilience: the role of procurement", Supply Chain Management: An International fournal, Vol. 19 Nos 5/6, pp. 626-642.

Pettit, T.J., Croxton, K.L. and Fiksel, J. (2013), "Ensuring supply chain resilience: development and implementation of an assessment tool", fournal of Business Logistics, Vol. 34 No. 1, pp. 46-76.

Pettit, T.J., Fiksel, J. and Croxton, K.L. (2010), "Ensuring supply chain resilience: development of a conceptual framework", Fournal of Business Logistics, Vol. 31 No. 1, pp. 1-21.

Pimm, S.L. (1984), "The complexity and stability of ecosystems”, Nature, Vol. 307 No. 5949, pp. 321-326.

Ponis, S.T. and Koronis, E. (2012), "Supply chain resilience: definition of concept and its formative elements", fournal of Applied Business Research (FABR), Vol. 28 No. 5, pp. 921.

Ponomarov, S.Y. and Holcomb, M.C. (2009), "Understanding the concept of supply chain resilience", The International fournal of Logistics Management, Vol. 20 No. 1, pp. 124-143.

Popkin, B.M. (1999), "Urbanization, lifestyle changes and the nutrition transition", World Development, Vol. 27 No. 11, pp. 1905-1916.

Ratick, S., Meacham, B. and Aoyama, Y. (2008), "Locating backup facilities to enhance supply chain disaster resilience", Growth and Change, Vol. 39 No. 4, pp. 642-666.

Redman, C. (2014), "Should sustainability and resilience be combined or remain distinct pursuits", Ecology and Society, Vol. 19 No. 2, pp. 37.

Ritchie, B. and Brindley, C. (2007), "Supply chain risk management and performance: a guiding framework for future development", International fournal of Operations $\mathcal{G}$ Production Management, Vol. 27 No. 3, pp. 303-322.

Rodriguez-Nikl, T. (2015), "Linking disaster resilience and sustainability", Civil Engineering and Environmental Systems, Vol. 32 Nos 1/2, pp. 157-169.

Rose, A. (2011), "Resilience and sustainability in the face of disasters", Environmental Innovation and Societal Transitions, Vol. 1 No. 1, pp. 96-100.

Rousseau, D.M., Manning, J. and Denyer, D. (2008), "Evidence in management and organizational science: assembling the field's full weight of scientific knowledge through syntheses", The Academy of Management Annals, Vol. 2 No. 1, pp. 475-515.

Schmitt, A.J. and Singh, M. (2012), "A quantitative analysis of disruption risk in a multi-echelon supply chain", International Fournal of Production Economics, Vol. 139 No. 1, pp. 22-32. 
Scholten, K. and Schilder, S. (2015), "The role of collaboration in supply chain resilience", Supply Chain Management: An International fournal, Vol. 20 No. 4, pp. 471-484.

Scholten, K., Scott, P. and Fynes, B. (2014), "Mitigation processes-antecedents for building supply chain resilience", Supply Chain Management: An International foumal, Vol. 19 No. 2, pp. 211-228.

Sharifi, H. and Zhang, Z. (1999), "A methodology for achieving agility in manufacturing organisations: an introduction", International journal of production economics, Vol. 62 No. 1, pp. 7-22.

Sheffi, Y. (2001), "Supply chain management under the threat of international terrorism", The International fournal of Logistics Management, Vol. 12 No. 2, pp. 1-11.

Sheffi, Y. and Rice, J.R. (2005), "A supply chain view of the resilient enterprise", MIT Sloan Management Review, Vol. 47 No. 1, pp. 44.

Sinclair, K., Curtis, A., Mendham, E. and Mitchell, M. (2014), "Can resilience thinking provide useful insights for those examining efforts to transform contemporary agriculture?", Agriculture and Human Values, Vol. 31 No. 3, pp. 371-384.

Skipper, J.B. and Hanna, J.B. (2009), "Minimizing supply chain disruption risk through enhanced flexibility", International Fournal of Physical Distribution \& Logistics Management, Vol. 39 No. 5, pp. 404-427.

Smith, K., Lawrence, G., MacMahon, A., Muller, J. and Brady, M. (2016), "The resilience of long and short food chains: a case study of flooding in Queensland, Australia", Agriculture and Human Values, Vol. 33 No. 1, pp. 45-60.

Soni, U., Jain, V. and Kumar, S. (2014), "Measuring supply chain resilience using a deterministic modeling approach", Computers Eீ Industrial Engineering, Vol. 74, pp. 11-25.

Spiegler, V.L., Naim, M.M. and Wikner, J. (2012), “A control engineering approach to the assessment of supply chain resilience", International Fournal of Production Research, Vol. 50 No. 21, pp. 6162-6187.

Stecke, K.E. and Kumar, S. (2009), "Sources of supply chain disruptions, factors that breed vulnerability, and mitigating strategies”, fournal of Marketing Channels, Vol. 16 No. 3, pp. 193-226.

Stevenson, M. and Spring, M. (2007), "Flexibility from a supply chain perspective: definition and review", International Fournal of Operations $\mathcal{E}$ Production Management, Vol. 27 No. 7, pp. 685-713.

Suweis, S., Carr, S., Maritan, A., Rinaldoc, A. and D'Odorico, P. (2015), "Resilience and reactivity of global food security", Proceedings of the National Academy of Sciences of Sciences, Vol. 112 No 34, pp. 4811.

Swafford, P.M., Ghosh, S. and Murthy, N. (2006), "The antecedents of supply chain agility of a firm: scale development and model testing", fournal of Operations Management, Vol. 24 No. 2, pp. 170-188.

Tang, C.S. (2006), "Robust strategies for mitigating supply chain disruptions", International fournal of Logistics Research and Applications, Vol. 9 No. 1, pp. 33-45.

Tang, O. and Musa, S.N. (2011), "Identifying risk issues and research advancements in supply chain risk management", International Fournal of Production Economics, Vol. 133 No. 1, pp. 25-34.
Taylor, D.H. and Fearne, A. (2006), "Towards a framework for improvement in the management of demand in Agri-food supply chains", Supply Chain Management: An International Fournal, Vol. 11 No. 5, pp. 379-384.

Tendall, D.M., Joerin, J., Kopainsky, B., Edwards, P., Shreck, A., Le, Q.B., Kruetli, P., Grant, M. and Six, J. (2015), "Food system resilience: defining the concept", Global Food Security, Vol. 6, pp. 17-23.

Thun, J.H. and Hoenig, D. (2011), “An empirical analysis of supply chain risk management in the German automotive industry", International fournal of Production Economics, Vol. 131 No. 1, pp. 242-249.

Todo, Y., Nakajima, K. and Matous, P. (2015), "How do supply chain networks affect the resilience of firms to natural disasters? Evidence from the great east Japan earthquake", Fournal of Regional Science, Vol. 55 No. 2, pp. 209-229.

Tomlin, B. (2006), "On the value of mitigation and contingency strategies for managing supply chain disruption risks", Management Science, Vol. 52 No. 5, pp. 639-657.

Tranfield, D., Denyer, D. and Smart, P. (2003), “Towards a methodology for developing evidence-informed management knowledge by means of systematic review", British fournal of Management, Vol. 14 No. 3, pp. 207-222.

Trkman, P. and McCormack, K. (2009), "Supply chain risk in turbulent environments - a conceptual model for managing supply chain network risk", International fournal of Production Economics, Vol. 119 No. 2, pp. 247-258.

Tukamuhabwa, B.R., Stevenson, M., Busby, J. and Zorzini, M. (2015), "Supply chain resilience: definition, review and theoretical foundations for further study", International Fournal of Production Research, Vol. 53 No. 18, pp. 5592-5623.

United Nations, Department of Economic and Social Affairs, Population Division (2015), "World population prospects: the 2015 revision, key findings and advance tables, Working Paper No. ESA/P/WP.241.

Van der Vorst, J.G. and Beulens, A.J. (2002), "Identifying sources of uncertainty to generate supply chain redesign strategies", International fournal of Physical Distribution \& Logistics Management, Vol. 32 No. 6, pp. 409-430.

Vlajic, J.V., van der Vorst, J.G. and Haijema, R. (2012), “A framework for designing robust food supply chains", International fournal of Production Economics, Vol. 137 No. 1, pp. 176-189.

Vlajic, J.V., van Lokven, S.W., Haijema, R. and van der Vorst, J.G. (2013), "Using vulnerability performance indicators to attain food supply chain robustness", Production Planning $\mathcal{E}$ Control, Vol. 24 Nos 8/9, pp. 785-799.

Wagner, S.M. and Bode, C. (2008), “An empirical examination of supply chain performance along several dimensions of risk", Fournal of Business Logistics, Vol. 29 No. 1, pp. 307-325.

Wagner, S.M. and Neshat, N. (2010), "Assessing the vulnerability of supply chains using graph theory", International Fournal of Production Economics, Vol. 126 No. 1, pp. 121-129.

Wagner, S.M. and Neshat, N. (2012), "A comparison of supply chain vulnerability indices for different categories of firms", International fournal of Production Research, Vol. 50 No. 11, pp. 2877-2891. 
Walker, B., Gunderson, L., Kinzig, A., Folke, C., Carpenter, S. and Schultz, L.A. (2006), "A handful of heuristics and some propositions for understanding resilience in social-ecological systems", Ecology and Society, Vol. 11 No. 1.

Wang, Y., Chen, C., Wang, J. and Baldick, R. (2016), "Research on resilience of power systems under natural disasters-A review", IEEE Transactions on Power Systems, Vol. 31 No. 2, pp. 1604-1613.

Wieland, A. and Wallenburg, C.M. (2013), "The influence of relational competencies on supply chain resilience: a relational view", International Fournal of Physical Distribution \& Logistics Management, Vol. 43 No. 4, pp. 300-320.

World Commission on Environment and Development (WCED) (1987), Our Common Future, Oxford University Press, New York, NY.

Wu, T., Huang, S., Blackhurst, J., Zhang, X. and Wang, S. (2013), "Supply chain risk management: an agent-based simulation to study the impact of retail stockouts", IEEE Transactions on Engineering Management, Vol. 60 No. 4, pp. 676-686.

Yang, Y. and Xu, X. (2015), "Post-disaster grain supply chain resilience with government aid", Transportation Research Part E: Logistics and transportation review, Vol. 76, pp. 139-159.

Zacharia, Z.G., Nix, N.W. and Lusch, R.F. (2009), "An analysis of supply chain collaborations and their effect on performance outcomes", fournal of Business Logistics, Vol. 30 No. 2, pp. 101-123.

Zsidisin, G.A. and Wagner, S.M. (2010), "Do perceptions become reality? The moderating role of supply chain resiliency on disruption occurrence", fournal of Business Logistics, Vol. 31 No. 2, pp. 1-20.

\section{Further reading}

Barroso, A.P. and Machado, V.H. (2011), "Supply chain resilience using the mapping approach", Supply Chain Management, pp. 161-181.

\section{About the authors}

Jamie Stone holds a BSc in Medical Microbiology and Virology from The University of Warwick (2010) and an MSc in Food Security also from The University of Warwick (2012). Jamie has experience in the field of sustainable development in a UK setting with Localise West Midlands (2012) and in an international development context with APT Action on Poverty (2013). He joined Loughborough University in 2014 as a Doctoral Research Student with the Centre for Sustainable Manufacturing and Recycling Technologies. His research explores factors which reduce vulnerability and thus increase resilience of food supply chains to external volatility, with a particular focus on food manufacturing in the UK. This work is carried out within the EPSRC Centre for Innovative Manufacturing in Food against the broader context of sustainable manufacturing of food and global food security. Jamie Stone is the corresponding author and can be contacted at: j.stone@lboro.ac.uk

Shahin Rahimifard holds a BSc in Computing and Mathematics from Brighton University, an MSc in Computer Integrated Manufacturing and a $\mathrm{PhD}$ in Operational Planning of Manufacturing Systems both from Loughborough University. He has over 20 years of experience in managing $\mathrm{R} \& \mathrm{D}$ projects within the field of sustainable manufacturing at Loughborough University. As a Founder and a Director of the Centre for Sustainable Manufacturing and Recycling Technologies (SMART) in Loughborough, he has been involved in over 25 national and European research projects. His research interests are sustainable product design, low carbon manufacturing, environmentally focussed production planning and supply chain management and product recovery, reuse and recycling technologies. He has over 90 publications associated with his work. Prof. Rahimifard has been the Editor-in-Chief of the International fournal of Sustainable Engineering since 2008, and he is the book review editor for three other international journals. $\mathrm{He}$ is also a member of the Technical Committee for four international conferences. 